\title{
Constraining the $\mathrm{CO}_{2}$ budget of the corn belt: exploring uncertainties from the assumptions in a mesoscale inverse system
}

\author{
T. Lauvaux ${ }^{1}$, A. E. Schuh ${ }^{2,5}$, M. Uliasz ${ }^{5}$, S. Richardson ${ }^{1}$, N. Miles ${ }^{1}$, A. E. Andrews ${ }^{4}$, C. Sweeney ${ }^{4}$, L. I. Diaz ${ }^{1}$, \\ D. Martins ${ }^{1}$, P. B. Shepson ${ }^{3}$, and K. J. Davis ${ }^{1}$ \\ ${ }^{1}$ Department of Meteorology, The Pennsylvania State University, Inversity Park, Pennsylvania, USA \\ ${ }^{2}$ NREL, Fort Collins, Colorado, USA \\ ${ }^{3}$ Purdue University, W. Lafayette, Indiana, USA \\ ${ }^{4}$ National Oceanic and Atmospheric Association, ESRL/GMD, Boulder, Colorado, USA \\ ${ }^{5}$ Department of Atmospheric Science, Colorado State University, Fort Collins, Colorado, USA
}

Correspondence to: T. Lauvaux (lauvaux@ meteo.psu.edu)

Received: 27 June 2011 - Published in Atmos. Chem. Phys. Discuss.: 22 July 2011

Revised: 8 November 2011 - Accepted: 13 December 2011 - Published: 5 January 2012

\begin{abstract}
We performed an atmospheric inversion of the $\mathrm{CO}_{2}$ fluxes over Iowa and the surrounding states, from June to December 2007, at $20 \mathrm{~km}$ resolution and weekly timescale. Eight concentration towers were used to constrain the carbon balance in a $1000 \times 1000 \mathrm{~km}^{2}$ domain in this agricultural region of the US upper midwest. The $\mathrm{CO}_{2}$ concentrations of the boundaries derived from CarbonTracker were adjusted to match direct observations from aircraft profiles around the domain. The regional carbon balance ends up with a sink of $183 \mathrm{Tg} \mathrm{C} \pm 35 \mathrm{TgC}$ over the area for the period June-December, 2007. Potential bias from incorrect boundary conditions of about $0.55 \mathrm{ppm}$ over the 7 months was corrected using mixing ratios from four different aircraft profile sites operated at a weekly time scale, acting as an additional source of uncertainty of $24 \mathrm{Tg} \mathrm{C}$. We used two different prior flux estimates, the SiBCrop model and the inverse flux product from the CarbonTracker system. We show that inverse flux estimates using both priors converge to similar posterior estimates ( $20 \mathrm{Tg} \mathrm{C}$ difference), in our reference inversion, but some spatial structures from the prior fluxes remain in the posterior fluxes, revealing the importance of the prior flux resolution and distribution despite the large amount of atmospheric data available. The retrieved fluxes were compared to eddy flux towers in the corn and grassland areas, revealing an improvement in the seasonal cycles between the two compared to the prior fluxes, despite large absolute differences due to representation errors. The uncertainty of $34 \mathrm{Tg} \mathrm{C}$ (or
\end{abstract}

$34 \mathrm{~g} \mathrm{C}^{2}$ ) was derived from the posterior uncertainty obtained with our reference inversion of about 25 to $30 \mathrm{TgC}$ and from sensitivity tests of the assumptions made in the inverse system, for a mean carbon balance over the region of $-183 \mathrm{Tg} \mathrm{C}$, slightly weaker than the reference. Because of the potential large bias ( $\sim 24 \mathrm{TgC}$ in this case) due to choice of background conditions, proportional to the surface but not to the regional flux, this methodology seems limited to regions with a large signal (sink or source), unless additional observations can be used to constrain the boundary inflow.

\section{Introduction}

Atmospheric inversions have been used to quantify the exchanges of $\mathrm{CO}_{2}$ between the atmosphere and the continents, and the atmosphere and the oceans, each of them contributing to a significant part of the global carbon cycle (Tans et al., 1990; Francey et al., 1995; Bousquet et al., 2000; Chevallier et al., 2010). Uncertainties and variability amongst studies remain large (Gurney et al., 2002), especially for the continental surface exchanges that are highly variable in time and space and closely related to land use change, climate variability and ecosystem responses to environmental changes (Canadell et al., 2007). The misrepresentation of atmospheric processes in the transport models (Baker et al., 2007; Stephens et al., 2007), the lack of available measurements

Published by Copernicus Publications on behalf of the European Geosciences Union. 
around the globe responsible for the ill-conditionning of the problem at large scales (Enting, 2002), and the errors of representation at the scales they have been performed (Geels et al., 2007), limit the potential of the method.

Several studies attempted to reduce these major sources of uncertainties by improving temporal and spatial resolutions, from global to continental scales solving for homogeneous flux areas called ecoregions (Peters et al., 2007; Butler et al., 2010), or pixel-based fluxes (Carouge et al., 2010; Gourdji et al., 2010; Schuh et al., 2010), and from continental to regional domains (Lauvaux et al., 2009a; Göckede et al., 2010a).

Refinement of the resolution requires the deployement of high density measurement networks in order to solve for the increasing number of unknowns in the state vector. Past campaigns were limited to a few surface tower sites or flights for a short period of time as CERES (CarboEurope Regional Experiment Strategy) (Dolman et al., 2006) or for very limited areas as in the bay of Valencia, (i.e. during the RECAB campaign, Pérez-Landa et al., 2007). Second, the bounded simulation domain becomes an important limitation if not well-informed of the $\mathrm{CO}_{2}$ inflow and requires the accurate knowledge of concentrations representing the far field influence (Rödenbeck et al., 2009). The boundaries require then additional observation datasets to inform the system about potential biases due to incorrect carbon mass in the air flow. Third, as inverse methods rely on a sufficiently good prior flux estimate, the performances of terrestrial ecology models need to be enhanced by finer vegetation description, especially its phenology, and a good description of the diurnal variability (Corbin et al., 2008; Gourdji et al., 2010). Finally, the mesoscale atmospheric transport models, even if better able to simulate the atmospheric dynamics driving hourly concentrations compared to general circulation models (Ahmadov et al., 2007), are still affected by transport errors from parametrizations of the Planetary Boundary Layer dynamics in particular (Gerbig et al., 2005; Sarrat et al., 2007a).

More recent studies have shown the potential of the atmospheric inversion methodology at the mesoscale (Lauvaux et al., 2009a). The evaluation of the inverse fluxes was limited to 18 days at $8 \mathrm{~km}$ resolution, but this study demonstrated for the first time the improvement of the fluxes in time and space against direct flux measurements from aircraft (Gioli et al., 2004). Over longer timescales, relatively small biases at short time scales become increasingly important leading to large final uncertainties at the annual time scale (Schuh et al., 2010). Even if the use of high temporal frequency data increases the amount of information in the system (Law et al., 2003), the flow-dependence of the error structures in the observation space increases with data density too, shown through model error propagation (Lauvaux et al., 2009b) or variograms of model-data mismatch (Gerbig et al., 2003b). Finally, flux errors from ecosystem models used to generate prior fluxes can be correlated, but studies at different time scales and using different models revealed a variety of spatial error correlation structures from large (Peylin et al., 2005) to very small (Chevallier et al., 2006) length scales.

In this study, we developed a mesoscale inversion at $20 \mathrm{~km}$ resolution generating inverse fluxes from June (start of the measurement campaign) to December 2007, at a weekly time scale (7.5 days), over the Mid Continent Intensive (MCI) domain, including Iowa and the surrounding states, known as the "Corn Belt" area. This unique instrumental deployement of concentration towers (Miles et al., 2010) and the presence of the National Oceanic and Atmospheric Administration (NOAA) aircraft profile sites (Sweeney et al. (2011), http:// www.esrl.noaa.gov/gmd/ccgg/aircraft/index.html) enable the most data-constrained regional inversion. The abundance of crops in the area (corn, soybean, wheat) includes $\mathrm{C}_{4}$ and $\mathrm{C}_{3}$ vegetation types, with a contribution of 20 to $40 \%$ by $\mathrm{C}_{4}$ crops on the growing season gross photosynthetic $\mathrm{CO}_{2}$ exchange (Griffis et al., 2010). The apparent atmospheric sink, due to the prevention of the decomposition of crop material after harvest, is one of the largest contributions to the overall US carbon budget annually (West et al., 2011), even though this carbon is released by livestock and humans elsewhere in the country during the following year. The strength of the atmospheric signals and the observation network are optimal conditions to test the potential of an atmospheric inversion at the regional scale.

We first describe the system and the different models used to generate the transport fields used to link concentrations to fluxes and their related uncertainties (cf. Sect. 2). Then we estimate the inverse fluxes using two different prior fluxes over the area, one being the direct results of the vegetation model SiBcrop (Lokupitiya et al., 2009) and second the product from the CarbonTracker inverse system (Peters et al., 2007), that we compared to several eddy flux sites over corn and grass ecosystems (cf. Sect. 3). We ran several sensitivity tests and demonstrate the importance of the different components of the system, especially the assumptions made in the error covariance matrices, the potential errors due to boundary conditions, and tested the potential of the system in a more general case. Finally, the remaining uncertainties and the potential of the inverse system are discussed in Sect. 4 .

\section{The inverse system}

\subsection{Analytical inversion framework}

The inverse system used in this study is an analytical inversion framework (Tarantola, 2004) correcting for temporally averaged fluxes over 7.5 day periods, separated into the averaged daytime (6 a.m. to 6 p.m.) and nighttime (7 p.m. to 5 a.m.) components at $20 \mathrm{~km}$ resolution, and boundary mixing ratios. We solved the inverse problem using the classical matrix solution by minimizing the cost function $F$ defined as follows:

$F=\frac{1}{2}\left[\left(x-x_{0}\right)^{T} B^{-1}\left(x-x_{0}\right)+(H x-y)^{T} R^{-1}(H x-y)\right]$ 
where $\boldsymbol{x}$ are the unknown flux vector we invert for, $\boldsymbol{x}_{0}$ the a priori flux estimate, $\boldsymbol{y}$ the observations, $H$ the influence functions, and $R$ and $B$ the uncertainty covariance matrices of the observations and the fluxes respectively. The control vector $\boldsymbol{x}$ includes the surface fluxes and the pre-processed boundary mixing ratios, and the influence function $H$ describes the relationship between the observed mixing ratios, the surface fluxes, and the pre-processed boundary mixing ratios. Minimizing the equation with respect to $x$ yields:

$\boldsymbol{x}=\boldsymbol{x}_{0}+B H^{T}\left(H B H^{T}+R\right)^{-1}\left(\boldsymbol{y}-H x_{0}\right)$

We can define the posterior error covariance $\boldsymbol{A}$ for sources given by the following expression:

$A^{-1}=B^{-1}+H^{T} R^{-1} H$

For the boundaries, we defined two different time frequencies that are applied to the different boundary condition time series for each tower: hourly, and every $90 \mathrm{~h}$, as explained in Sect. 2.5.3. In our inversion, the contributions of the boundary conditions to the modeled concentrations (referred as boundary conditions) are defined for each tower separately and only vary in time (i.e. no spatial description of the inflow in the inversion). The initial boundary condition is computed in the direct simulation and corresponds to the influence of the boundaries at the observation location. The spatial component is also considered during the pre-processing using the aircraft data and the influence functions (one for each boundary) to correct for biases. In the inversion, we adjust the overall inflow for each tower and at each time step using the surface tower mixing ratios but no explicit adjoint model. The final state vector dimension, on a grid of $980 \times 980 \mathrm{~km}$ at $20 \mathrm{~km}$ resolution (49 grid points in each direction) and for two components (nighttime and daytime), ranges from $49 \times 49 \times 2+2 \times 8=4818$ ( 90 hour frequency at the boundaries, or 2 unknowns per observation sites over $180 \mathrm{~h}$ ) to $49 \times 49 \times 2+180 \times 8=6242$ (hourly frequency at the boundaries, or 180 unknowns per tower). The observations are at the hourly frequency $(180 \times 8=1440$ observations per 7.5 days). One of our inversion setups includes observation error correlations depending on the time of the day, but not our reference setup. The transport error correlations were defined at similar scales but not for the transport model used in this study. As a conservative choice, error correlations were used only in the sensitivity experiments (cf. Sect. 3.6). The system is more constrained than past studies thanks to the large amount of data over the domain (1440 atmospheric observations versus 4818 to 6242 unknowns). Inverse fluxes over 7.5 day periods are decorrelated from one period to the next, considering the low temporal correlations in daily averaged flux errors over few days (Chevallier et al., 2006).

\subsection{Mixing ratio towers over the MCI}

We used hourly $\mathrm{CO}_{2}$ mixing ratios from seven towers all located in the Mid Continent Intensive Experiment area (Miles

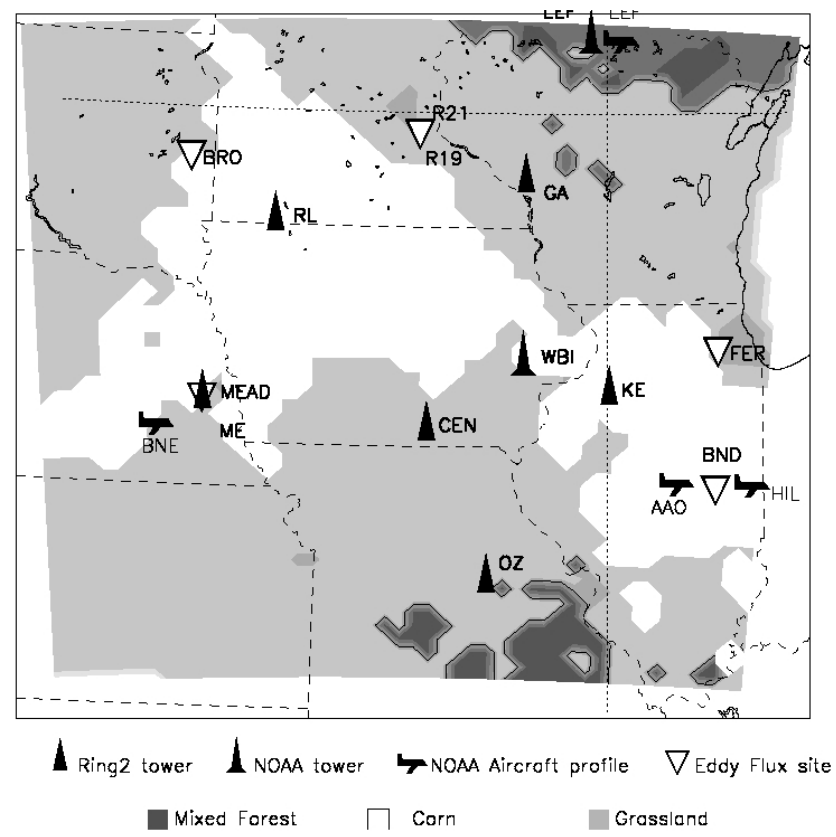

Fig. 1. The Mid Continent Intensive domain with the dominant plant functional types and the observation locations including the concentration tower sites used in the inversion (Ring2 and NOAA towers), the boundary conditions (NOAA aircraft profiles), and the eddy-flux sites used to evaluate the posterior fluxes.

et al., 2010), part of the North American Carbon Program (Ogle et al., 2006) (cf. Fig. 1). Five of them were deployed from 2007 to 2009 as additional sites for inversion purposes, on $\sim 100 \mathrm{~m}$ high towers, located in and out of the corn belt area: Centerville, Mead, Round Lake, Galesville, and Kewanee (Fig. 1). These five sites were equiped with cavity ring-down analyzers (Crosson, 2008), calibrated daily, and related measurement errors are $0.2-0.3 \mathrm{ppm}$ for the hourly averages (Richardson et al., 2011). One Ameriflux site, Missouri Ozarks (Gu et al., 2006), on a $40 \mathrm{~m}$ tower was calibrated during the period to provide an additional observation site during our study period. Finally, two NOAA tall tower sites were also available in the area: Park Falls (LEF), and West Branch (WBI). We used 100m sampling heights from all the sites to remain consistent. Compared to previous regional campaigns, the large number of observation sites offers the unique opportunity to constrain the regional carbon balance and assess the full potential of such methodology. Mixing ratio data were recorded every two minutes, and averaged to hourly resolution for this study.

\subsection{The prior fluxes and their associated errors}

Two prior flux estimates are used in this study: the first is the direct simulation of $\mathrm{CO}_{2}$ Net Ecosystem Exchange (NEE) with the SiBcrop vegetation model (Lokupitiya et al., 2009), and the second is the optimized flux estimate from the 
CarbonTracker inverse system (Peters et al., 2007). The $\mathrm{CO}_{2}$ fluxes of the first prior were simulated using the Simple Biosphere model including the recent developments of crop phenology and physiology (SiBcrop) at $10 \mathrm{~km}$ resolution and at hourly time step, forced by the NARR meteorological renalysis product (North American Regional Reanalysis). This version of SiB (Lokupitiya et al., 2009) includes a parametrization of the Leaf Area Index (LAI) and the fraction of Photosynthetically Active Radiation (fPAR) for crops that showed better agreement in comparison to eddy flux sites than previous NDVI-derived phenology. The allocation of carbon to the different pools (leaves, roots, stems, flowers,...) is estimated on a daily basis, the leaf pool being used to estimate the LAI, and the crop harvest takes place after maturity of the plants. In each pixel, three fluxes corresponding to the three dominant vegetation types are computed. The total flux corresponds to the sum of the three fluxes weighed by their relative vegetation fraction. The second prior fluxes used in this study are the inverse flux estimates from CarbonTracker 2009 system $\left(\mathrm{CT}_{v 09}\right)$ for the year 2007 , computed at a $1^{\circ}$ by $1^{\circ}$ resolution, and a 3 hourly time step over North America (Peters et al., 2007). The CarbonTracker inverse system uses atmospheric mixing ratios from the NOAA global network of surface stations to optimize surface fluxes over large ecoregions. Compared to the present inversion system, the spatial patterns in the inverse fluxes are prescribed for these ecoregions to compensate for the lack of observational constraint. The initial fluxes used in the CarbonTracker inverse system comes from the Carnegie-Ames Stanford Approach (CASA) biogeochemical mode ${ }^{1}$, which lacks a description of applied phenology that is specific to crops. A linear interpolation was applied to generate hourly fluxes. Most of the towers used in our inversion are not currently used in $\mathrm{CT}_{v 09}$, only WBI and LEF. These two prior fluxes were used to investigate the importance of the spatial and temporal distribution of the prior fluxes on the final retrieved estimates. We also assess the degree to which the regional cumulative flux will converge given very different priors (Sibcrop with a JuneDecember balance of $109 \mathrm{Tg} \mathrm{C}$ sink, and $\mathrm{CT}_{v 09}$ final product with $198 \mathrm{Tg} C$ sink) over the region. We also investigated the robustness of the system by adding substantial biases in the prior fluxes in summer and winter (cf. Sect. 4).

We quantified prior flux uncertainties based on the weekly flux model-data mismatch at several locations within the domain (cf. Sect. 2.6). We first defined the standard deviations as the maximum difference observed during the year between the weekly averaged modelled and observed NEE for the three most represented vegetation types of the region (corn, soybean, and grassland). This maximum model-data mismatch is then normalized for every week following the seasonal variability of the absolute fluxes (from 1 to 0.2 ), to define a weekly standard deviation. The combination of the observed seasonal cycle and the maximum model-data mis-

\footnotetext{
${ }^{1}$ http://geo.arc.nasa.gov/sge/casa/
}

match limits representation errors between site-level observations and grid point modeled fluxes. The final standard deviations represent 30 to $50 \%$ of the weekly net fluxes, and 40 to $70 \%$ of the total mismatch once projected in the observation space. The uncertainty assessment was finally controlled by computing the reduced $\chi^{2}$ value. Depending on the plant functional type (PFT), the maximum values for the standard deviations range in the growing season from $5 \mu \mathrm{mol} \mathrm{m}{ }^{-2} \mathrm{~s}^{-1}$ for grassland to $10 \mu \mathrm{mol} \mathrm{m}^{-2} \mathrm{~s}^{-1}$ for corn, and 1 to $5 \mu \mathrm{mol} \mathrm{m}{ }^{-2} \mathrm{~s}^{-1}$ during fall and winter. Error flux correlations are based on the vegetation cover map combined with an averaged correlation length. We defined the ecosystem spatial error correlation as the minimum of the vegetation fraction for one given ecosystem in the two pixels (following the SiBcrop ecosystem classification, from Lokupitiya et al., 2009), usually from 0.4 to 0.8 , as follows:

$C_{m, n}^{\mathrm{eco}_{1}}=\min \left(f_{m}^{\mathrm{eco}_{1}}, f_{n}^{\mathrm{eco}_{1}}\right)$

with $C_{m, n}^{\mathrm{eco}}$ the correlation coefficient between the pixel $m$ and the pixel $n$ for the ecosystem type $\mathrm{eco}_{1}$, and $f^{\mathrm{eco}_{1}}$ the fraction of vegetation for $\mathrm{eco}_{1}$ in one given pixel. We considered only the three major ecosystem types of each pixel. For example, two pixels including respectively $25 \%$ and $60 \%$ of corn will end up with .25 correlation coefficient. We combined this ecosystem-based error correlation with a distancebased error correlation (exponentially decaying correlation in space with a correlation length $L$ ) to create the final prior error correlation tensor as in Lauvaux et al. (2009b) by:

$\boldsymbol{C}^{\prime}=\left(\boldsymbol{C}_{\mathrm{eco}}^{1 / 2} \boldsymbol{C}_{\mathrm{dist}}^{1 / 2}\right)\left(\boldsymbol{C}_{\mathrm{eco}}^{1 / 2} \boldsymbol{C}_{\mathrm{dist}}^{1 / 2}\right)^{T}$

with the associated correlation tensors, $\boldsymbol{C}_{\text {eco }}$ for the ecosystem component and $\boldsymbol{C}_{\mathrm{dist}}$ for the distance component, and $\boldsymbol{C}^{\prime}$ the correlation matrix in the control variable space. The definition of the correlation length $L$ in $\boldsymbol{C}_{\mathrm{dist}}$, based on previous studies, is highly uncertain. For example, at the monthly timescale, Chevallier et al. (2006) showed no significant spatial correlations in the model-data mismatch. Other studies have used large error correlation lengths (Peylin et al., 2005; Schuh et al., 2010), with an isotropic distance-based distribution (Carouge et al., 2010). In the current inverse system, several tests showed that correlation lengths of more than $50 \mathrm{~km}$ showed very similar results in terms of inverse fluxes, primarily due to the large observational constraint on the fluxes. Past studies estimated clear spatial structures for crops at short distances $(\leq 100 \mathrm{~km})$ (Lauvaux et al., 2009a). We decide here to use $L=300 \mathrm{~km}$ as correlation length, decreased by the combination of ecosystem-based correlations. As a comparison, the overall uncertainty on the prior is similar to $L=100 \mathrm{~km}$ without considering the ecosystem influence. The choice of the error correlation length does impact the posterior uncertainties and further investigations will be performed in forthcoming studies. The prior error variances were finally slightly modified to adjust the ratio between the observational constraint and the prior errors. We used the 
reduced $\chi^{2}$ value to adjust the flux error variances (Kaminski et al., 2001). However, the adjustment of the flux errors remains lower than $10 \%$ compared to the initial estimates.

\subsection{Influence functions and atmospheric transport model errors}

\subsubsection{Atmospheric transport model WRF-CHEM}

The atmospheric transport model used in this study is the Weather Research Forecast model (Skamarock et al., 2005), including the chemistry module slightly modified here for $\mathrm{CO}_{2}$ (referred to as WRF-ChemCO ${ }_{2}$ ). The simulation domain is centered on Iowa, covering $1000 \mathrm{~km}$ by $1000 \mathrm{~km}$ at a $10 \mathrm{~km}$ resolution (Fig. 1). The atmospheric boundary layer scheme used is the Mellor-Yamada-Nakanishi-Niino (MYNN) 2.5 scheme (Nakanishi and Niino, 2004) coupled to the Monin-Obukhov (Jancic Eta) scheme for the surface physics. The atmospheric vertical column was described by 60 levels, with 40 levels in the lower $2 \mathrm{~km}$, the first level being at about $20 \mathrm{~m}$ above ground. The NOAH land surface model (Chen and Dudhia, 2001) was used to simulate the surface energy balance, and the National Centers for Environmental Prediction (NCEP) Eta/NAM model analysis product at $40 \mathrm{~km}$ resolution was used for the initial and boundary meteorological and surface conditions.

\subsubsection{Lagrangian particle dispersion modeling}

The influence functions, representing the relationship between concentrations at the tower locations and their related flux footprints at the surface, were simulated with the Lagrangian Particle Dispersion Model from Uliasz (1994). The mean winds $(\mathrm{u}, \mathrm{v}, \mathrm{w})$, potential temperature, and turbulent kinetic energy from the WRF-Chem $\mathrm{CO}_{2}$ simulations are used as input variables each $30 \mathrm{~min}$ to drive the particle motions from the receptor locations (receptor oriented framework), as described in Lauvaux et al. (2008). 1800 particles are released incrementally at equal intervals over one hour periods to describe the influence functions for every hourly observations. We also ran an additional Lagrangian simulation with a limited number of particles (180 per hour) to describe the boundary influence. In this study, we used the boundary influence functions to relate every observations with one of the four cardinal directions, in and above the planetary boundary layer (PBL). The method is described in Sect. 2.5. The final resolution of the inversion was degraded to $20 \mathrm{~km}$ at the surface for computational efficiency of the system, which remains adequate considering the spatial dimensions of the flux patterns in the area.

\subsubsection{The MCI 2007 aircraft campaign}

For the quantification of vertical transport errors, we used aircraft observations, mainly vertical profiles of $\mathrm{CO}_{2}$ concentrations, that were measured using a twin-engine Beechcraft
Duchess (Garman et al., 2006) during summer 2007 over Iowa (Martins et al., 2009). The vertical profiles ranged from the surface to the lower free troposphere $(\sim 3 \mathrm{~km}$ a.g.l. $)$ with an approximate ascent/descent rate of $2.5 \mathrm{~m} \mathrm{~s}^{-1}$. A nondispersive infrared differential absorption spectrophotometer was used to detect dry mole fractions of $\mathrm{CO}_{2}$ every second, with an uncertainty of the measurements of $\pm 0.3 \mathrm{ppm}$ (Martins et al., 2009). In-flight calibrations were conducted every 3 min using a reference gas standard $(386.12 \mathrm{ppm})$ prepared at the NOAA Earth Systems Research Laboratory and traceable to the World Meteorological Organization Central Calibration Laboratory for $\mathrm{CO}_{2}$ (Zhao et al., 1997). Between 15 June to 25 June 2007, nine flights were performed in central Iowa, which corresponds to one to three flights every two days on average. Six flights including long transects and vertical profiles were used in this study to evaluate the atmospheric model performances.

\subsubsection{Atmospheric transport model errors}

We estimated the transport model errors in four different steps: (1) we evaluated the WRF modeling performance by comparing the simulated concentrations to observations from nine aircraft transects between June 17 and 25 June 2007 (with six flights presented here); (2) we avoided inconsistencies in the Lagrangian model simulation by removing observations showing large differences between the direct $\mathrm{CO}_{2}$ concentrations from WRF-ChemCO $\mathrm{CO}_{2}$ and the backward concentrations from the LPDM; (3) we computed the aggregation errors and adjoint model errors using the standard deviation of the difference between the direct WRF mixing ratios and the backward LPDM mixing ratios over each week; and (4) we defined for one setup of our sensitivity experiment the error correlations in the observation error covariance matrix from previous studies based on ensemble simulations (Lauvaux et al., 2009b).

We describe here the four steps in more detail. First, we evaluated the simulated PBL heights by comparing the $\mathrm{CO}_{2}$ vertical distributions to observed $\mathrm{CO}_{2}$ concentations from nine aircraft flights that occured between the 17 to 25 June 2007 (Martins et al., 2009). The aircraft campaign consisted of several transects located in central Iowa and encompassed variable altitudes, ranging from a few hundreds of meters above ground level (in the convective PBL) to a few thousand (in the free troposphere). We present results for six flights of the campaign with long transects and repeated vertical profiles. The PBL height errors are diagnosed from these flights for transition periods (morning to early afternoon) and well-mixed conditions (midday to late afternoon), and converted into mixing ratio uncertainties. Results are presented in Sect. 3.

Second, we compared the $\mathrm{CO}_{2}$ concentrations from the direct simulation (WRF-ChemCO ${ }_{2}$ ) to the backward generated concentrations from LPDM for the 8 towers over the 7 months. Both simulations are coupled to the Sibcrop fluxes at 
$10 \mathrm{~km}$ resolution. When the difference is larger than $2 \sigma$, the standard deviation in the observation error covariance matrix is increased such that the concentration is ignored.

Third, we estimated the potential biases between the two simulated concentrations. The standard deviation is added to the initial one (from the previous step). This part includes the errors in the adjoint and due to aggregation of the fluxes from $10 \mathrm{~km}$ to $20 \mathrm{~km}$. The results and the impacts are presented in Sect. 3.

Finally, we compared two estimates of temporal error correlations in the observation error covariance matrix. Because of the continuous flow of the atmosphere, errors affecting hourly observations are propagated through time and space. Lauvaux et al. (2009b) showed that spatial correlations are significant below a distance of $150 \mathrm{~km}$ between observation locations when using hourly observations, corresponding to a correlation length of 30 to $40 \mathrm{~km}$. Similarly, Gerbig et al. (2003a) found an exponentially decreasing correlation length of about $40 \mathrm{~km}$ from variograms of aircraft measurements. So we have not included any spatial correlation in the observation errors in regard of distances between towers in the present network $(>150 \mathrm{~km})$. But hourly observation errors are affected by temporal correlations. We used a description of the temporal error correlations for each hour of the day based on a previous ensemble of perturbed model simulations (Lauvaux et al., 2009b). For each hourly observation time step, the correlation coefficients with the following hours are prescribed. These correlation functions correspond to the propagation of errors from any hour of the day to the following hours. For example, large correlation coefficients relate one hour in the afternoon to the next ones (up to 0.6 for the first following hours) to lower values during the night (less than 0.4 for the first following hours). Lauvaux et al. (2009b) showed the conservation of the transport model error structures during the afternoons, whereas transitions to different stability conditions (mornings and late afternoons) tend to dissipate these structures. In our case, the error correlation functions are defined over $12 \mathrm{~h}$ (linking for example errors at 2 p.m. with the 12 following hours), or less if the correlation coefficient becomes negative (e.g., 8 p.m. error correlation function equals zero at 10 p.m.), meaning that the error structures disappear rapidly when the stability conditions are changing. Here, we defined our reference case with no temporal correlation because the correlation functions were computed with a different mesoscale model (MesoNH in this case), and over a different region. Though, we compare the impact of these error correlations in Sect. 3.6 to our reference inversion that assumes no temporal correlation to quantify their relative importance compared to other components of the system.

\subsection{Boundary conditions and aircraft observations}

The modeled $\mathrm{CO}_{2}$ mixing ratios can be decomposed in two seperate contributions: the local surface fluxes within the modeling domain, and the boundary conditions corresponding to the far field influence, i.e. the contribution of the $\mathrm{CO}_{2}$ inflow from the outer domain to the observed concentrations. We describe in this section the aircraft measurements used to correct initial model outputs, the pre-processing of the boundary mixing ratios to reduce the potential biases, and finally the estimation of their associated uncertainties. This pre-processing of the boundary conditions using aircraft flask data is done independently, before the inversion. The final corrected boundary conditions will be used as prior inflow in the flux inversion. Previous studies at the regional scale showed limited impact from the boundaries because of the oceanic influence and the orography, forcing the scale of the atmospheric processes to mesoscale circulation patterns. These campaigns were in summer, over short time periods (a few weeks), with little changes in the far-field influence compared to large local vegetation signals (Pérez-Landa et al., 2007; Sarrat et al., 2007b). Over longer time scales, systematic errors become increasingly important and need to be corrected (Göckede et al., 2010b).

\subsubsection{Weekly aircraft data from NOAA}

In this study, the flat terrain and the absence of orography around our domain allow large circulation patterns to affect the background air concentration through seasonal circulation patterns, longitudinal continental jets, and latitudinal conveyor systems as fronts pass (Wang et al., 2007). Here, aircraft data, and more specifically vertical profiles, were used to correct for biases and misrepresentation of the inflow. We used weekly flights operated by the Carbon Cycle Greenhouse Gases Aircraft Project (Sweeney et al., 2011) run by the NOAA's Earth System Research Laboratory (NOAA/ESRL). Four sites were selected to represent our four simulation boundaries: the Airborne Aerosol Observing near Bondville, Illinois (AAO), Beaver crossing in Nebraska (BNE), Homer in Illinois (HIL), and Park Falls in Wisconsin (LEF) (cf. Fig. 1). We compare flask data to modelled mixing ratios at the boundaries, for each week of the 7 months, and compute a correction which we apply to the inflow boundaries to remove or at least decrease biases by pre-processing of the boundary concentrations.

\subsubsection{Pre-processing of the boundary $\mathrm{CO}_{2}$ concentrations}

The boundary conditions are defined in two steps: first, we compute time series at each tower location. Second, these time series are used in the inversion system. But before adding these time series to the state vector in the inversion, we removed systematic errors with the help of aircraft measurements, and computed their associated uncertainties. The pre-processing of the boundaries helps to limit potential biases affecting boundary conditions. 
Four aircraft profile sites were selected to correct for potential biases in the $\mathrm{CT}_{v 09}$ mixing ratios. We attributed each of the four aircraft profile sites to one or two of the four cardinal boundaries. The choice of four cardinal boundaries is due to the lack of extensive datasets in space. We limit our correction here to the mean wind direction represented by the four boundaries of our domain. Two of the sites (AAO and HIL, cf. Fig. 1) located in the South East of the domain were both used to assess the South and East boundary corrections, LEF for the North boundary, and BNE for the West. The framework is presented in Fig. 2. First, we compared the aircraft profile mixing ratios to the modeled $\mathrm{CT}_{v 09}$ mole fractions integrated over two layers: one PBL contribution and one free tropospheric contribution. The PBL height is determined with the LPDM particle distribution over the column, defined by higher densities of particles within the PBL, directly related to the TKE profile from WRF. Second, we computed the model-data mismatches (North, South, East, West, with one PBL and one free tropospheric values) at the exact time of the flights, and averaged them if several flights were performed during the week. These weekly model-data mismatches represent the systematic errors, and are used to correct the initial boundary conditions from $\mathrm{CT}_{v 09}$. Finally, we have to apply the corrections at the boundaries on the time series computed at the tower locations. At each time step, a correction is applied on the value of the time series depending on the origin of the inflow. Over a week, hourly obervations are influenced by one or more boundaries (following the main wind direction changes). We identified the inflow origin with the particle distribution at the boundaries of the domain. The particles are counted over each week on the two levels and for each boundary. The selected mismatches were then removed from the initial $\mathrm{CT}_{v 09}$ inflow time series depending on the boundaries influencing the tower mixing ratios. These corrected values were then included in the inversion system as additional unknowns, described hereafter (cf. Sect. 2.5.3). The results are presented in Sect. 3.3.

\subsubsection{Optimization of the boundary $\mathrm{CO}_{2}$ concentrations in the inversion system}

The processed boundary conditions are now treated as additional unknowns in the inverse system, decreasing slightly the observational constraint by increasing the number of elements in the state vector (representing both the fluxes and the boundaries). In the system, we attribute part of the atmospheric signals to the boundaries following the uncertainties, i.e. no transport model is used to attribute atmospheric signals to the inflow at this step. A transport model was used previously to estimate systematic errors and relate the observations with the boundaries. Here, we only consider the inflow as an uncertainty instead of trying to optimize it without the help of additional observations.

The temporal window for the correction of the boundary conditions corresponds to the temporal variability of the

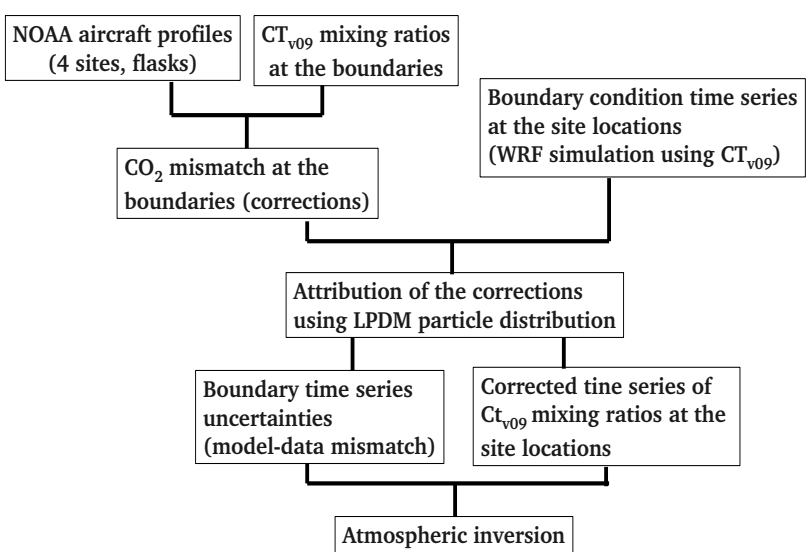

Fig. 2. Schematic framework of the boundary conditions including the mixing ratio pre-processing and the estimation of the uncertainties.

$\mathrm{CO}_{2}$ inflow. We chose two different temporal windows to invert for the boundaries at each tower: one hour, and 90 hours. The dimensions increase with $2 \times 8=16$ additional unknowns when using 90 -h averaged boundary mixing ratios or $180 \times 8=1440$ additional unknowns with hourly boundary mixing ratios. Hourly changes correspond to large gradients, whereas several days represent only synoptic changes. Theoretically, longer time windows imply longer temporal correlations in the boundary conditions. The implicit definition of the correlations in the state vector errors implies more than the physical duration of events but also the capacity of the system to invert for biased concentrations. $90 \mathrm{~h}$ (about four days) corresponds to the length of synoptic events affecting the inflow concentrations. In our study, we estimated the boundary condition uncertainties based on the standard deviations of the model-aircraft data mismatch, ranging from 2 to $4 \mathrm{ppm}$ at the hourly time step, and from 0.5 to $1 \mathrm{ppm}$ on $90 \mathrm{~h}$-averages.

Depending on the time of the day, the combination of the performance of the mesoscale model, the reproductability of the concentrations by the Lagrangian model, and the boundary condition uncertainties, the inverse system will distribute the atmospheric signals amongst the different components (nighttime and daytime surface fluxes, and boundary concentrations). We discuss in Sect. 4 the impact of these components and their related uncertainties associated on our final $\mathrm{CO}_{2}$ balance.

\subsection{Evaluation of the inverse fluxes: Eddy-flux sites over the MCI}

We used observed Net Ecosystem Exchange (NEE) measurements from six different eddy-covariance flux sites to evaluate the temporal patterns of the inverse analysis. Four are located in the corn area: Bondville (Meyers and Hollinger, 2004), Rosemount 21 and 19 (Baker and Griffis, 2004), and 


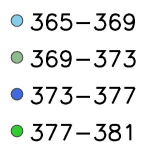

Observed CO2: ALAR campaign
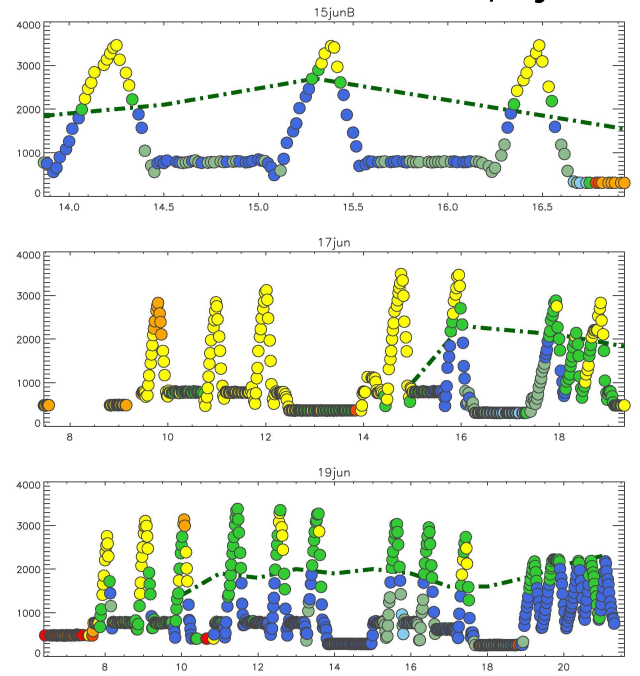

$0381-385$

- 385-389

- 389-393

- 393-397

WRF $\mathrm{CO} 2$ at $10 \mathrm{~km}$ resolution
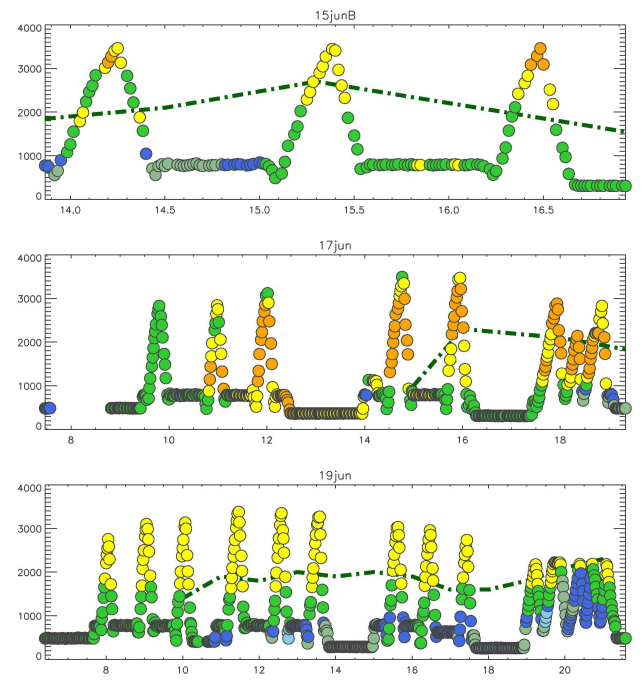

Fig. 3. $\mathrm{CO}_{2}$ concentrations observed during several flights of the ALAR campaign for 15,17 and 19 June (on the left) compared to WRF$\mathrm{ChemCO}_{2}$ concentrations using SiBcrop fluxes (=before flux optimization) (on the right). Colors indicate the mixing ratio range in ppm. The top of the PBL is indicated by the large vertical gradients from low to high mixing ratios in the free troposphere (green dashed line). The differences between observed and simulated PBL heights are large during transition periods (mornings), overwhelming signals during nighttime, but are low during daytime (afternoons), ranging from 10 to $15 \%$ of the PBL height.

Mead (with three sites on irrigated, rainfed, and irrigated with crop rotation ecosystems) (Verma et al., 2005), and two in grassland areas: Brookings and Fermi prairie sites (Matamala et al., 2008), all part of the Ameriflux network ${ }^{1}$ (Fig. 1). We focused our evaluation on the flux sites whose dominant landcover was corn or grassland in order to gauge the success of the inverse fluxes over the most represented ecosystems. The four eddy flux sites over corn are reliable indicators of the temporal variability but representation errors remain large when compared to our $20 \mathrm{~km}$ resolution inverse product. The ecosystem variability in one given grid point at $20 \mathrm{~km}$ resolution is far from negligeable. The fraction of corn in one pixel is between 40 to $60 \%$ in the corn belt area (referred here as corn-dominated pixels). Eddy flux measurements indicate larger uptake during the growing season, corn being the most active plant in term of photosynthetic activity at this time of the year (Verma et al., 2005). The uptake is larger by at least a factor of two during the maximum growth period (July) compared to other plant types. We used the seasonal cycle and the week-to-week variations to evaluate the temporal corrections in the inverse fluxes. We assume that the observed variability in the eddy-flux measurements is robust and well-correlated with larger scale variability, but too limited to be extrapolated to a region (Wang et al., 2006). We

\footnotetext{
${ }^{1}$ http://public.ornl.gov/ameriflux/
}

focus on temporal behaviour observed during the season and droughts occuring later in summer of the year 2007. We represented eddy flux site errors by the variations across sites, assuming that representation errors are dominant in our context.

\section{Results}

\subsection{Aircraft data and transport errors due to vertical mixing}

We analyze here model-data mismatch using prior fluxes and pre-processed boundary conditions to characterize the vertical structures of the lower troposphere and assign realistic uncertainties representing transport errors due to incorrect vertical mixing. The absolute concentration mismatch is not considered as an indication of transport errors as the $\mathrm{CO}_{2}$ flux errors represent the majority of the final mismatch. In Figs. 3 and 4, we show the simulated $\mathrm{CO}_{2}$ concentrations within $4 \mathrm{ppm}$-intervals represented by colored circles against aircraft observed concentrations during 6 different aircraft flights. The PBL heights defined by the vertical gradient in $\mathrm{CO}_{2}$ show relatively good agreement during the afternoon with differences of about 10 to $15 \%$, in the range of the observed variability of the entrainment zone depth between the convective boundary layer and the free troposphere (Grabon 
○ $365-369$

- $369-373$

- $373-377$

- $377-381$
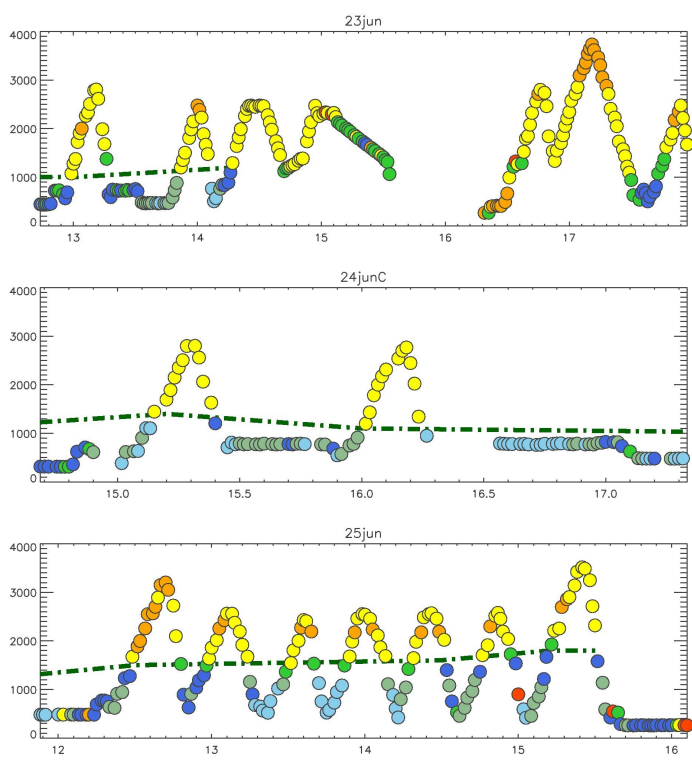

○ $381-385$

- $385-389$

- 389-393

- 393-397
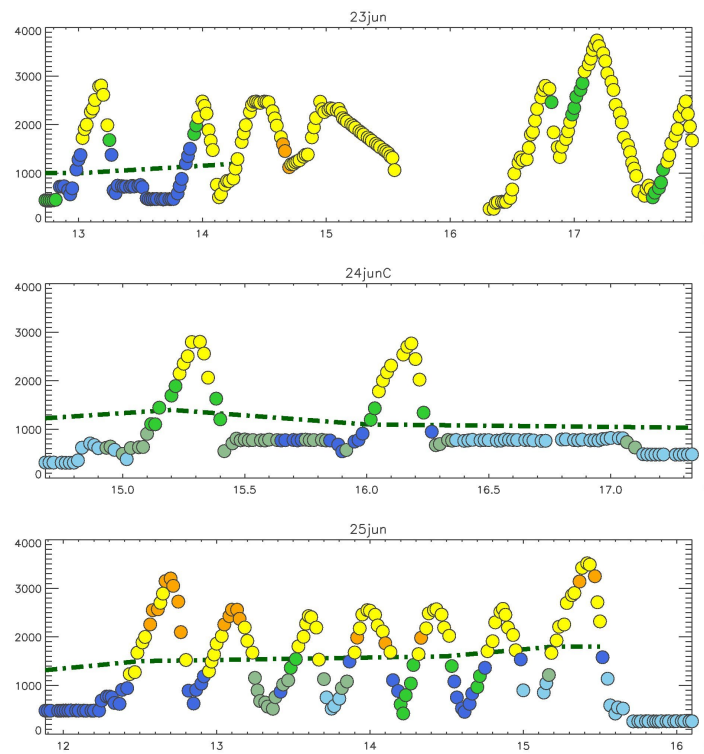

Fig. 4. Same figure for 23, 24 and 25 June flights.

et al., 2010), whereas transition periods are not well captured by the model. In the early morning (19 June, 7 a.m. to 10 a.m.), the PBL is well-developed in the model whereas no vertical gradient between the PBL and the free troposphere is observed during the flight. In the late afternoon (17 and 19 June, from 7 p.m. to 9 p.m.), the vertical distributions of $\mathrm{CO}_{2}$ are simulated well by the model. We defined the standard deviations (diagonal terms of the $R$ matrix) based on this comparison by assigning large errors during the late morning (10 a.m.-12 p.m.) of 30 to $50 \%$ of the total modeldata mismatch, then smaller errors of 10 to $15 \%$ of the signal as transport errors ( 2 to $3 \mathrm{ppm}$ in summer on average) during the well-mixed conditions, and finally very large errors for nighttime concentrations (after 8pm) that almost remove entirely the observational constraint during these hours $\left(\sigma_{\text {night }}=100 \mathrm{ppm}\right)$.

\subsection{Backward/Forward transport comparison}

We evaluate the internal consistency of our forward and inverse modeling systems which represents the adjoint and the aggregation errors. We also eliminate time periods when there are significant discrepancies between forward and backward simulated mixing ratios. We do this by computing the $\mathrm{CO}_{2}$ mixing ratios predicted at the tower sites using the same prior fluxes with both WRF-chem and LPDM, and compare these hourly estimates over the entire 7-month period of study.
The initial mismatch between the Eulerian model (WRFchem) and the Lagrangian model (LPDM) is affected by large differences in the concentration time series during a few days per month (one isolated day or few hours). These larges biases are correlated with more stable conditions in the lower atmosphere and indicates clear disagreements between the Lagrangian model and the Eulerian simulations. We applied a filter to remove these periods in our inverse system by increasing observation errors to $100 \mathrm{ppm}$ for these observations. The assigned weights are equivalent to neglect these observations. The threshold that we chose as indicative of inconsistent dynamics, is $2 \sigma$ of the residual distribution (defined as the square root of the mean square of the half-hourly model-model difference), where $\sigma$ is computed on a weekly basis for each tower. This threshold ranges from 2 to $7 \mathrm{ppm}$ depending on the season and the tower. We re-compute the daytime biases after removing the large mismatch periods. In summer, when the $\mathrm{CO}_{2}$ surface flux is large (implying large atmospheric signals), the standard deviation of the residuals are now lower than $\pm 2.2 \mathrm{ppm}$, and show an averaged summer bias of $0.12 \mathrm{ppm}$.

We then added an uncertainty corresponding to the standard deviation for each week of 1 to $2 \mathrm{ppm}$ to the initial WRF errors (diagonal terms in $R$ ) for the misrepresentation of the Eulerian dynamics by the Lagrangian model based on these results. During winter, weekly and seasonal biases are much lower, respectively less than $1.9 \mathrm{ppm}$ at the hourly time scale and equal to $0.1 \mathrm{ppm}$ on average. But 


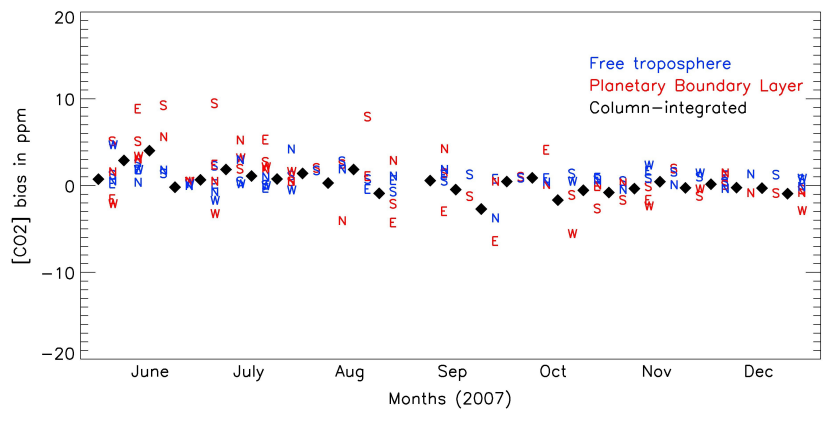

Fig. 5. $\mathrm{CO}_{2}$ concentration differences between the observed $\mathrm{CO}_{2}$ concentrations by the aircraft and simulated by $\mathrm{CT}_{v 09}$ at the four aircraft sites (indicated by the cardinal directions) in the Planetary Boundary Layer (in red), the free troposphere (in blue), and columnaveraged PBL (black diamonds).

the surface flux contribution to the atmospheric variability is lower, which explains the apparent smaller mismatch. We defined the additional uncertainties using the same methodology as for summer, from 0.2 to $0.9 \mathrm{ppm}$ for the variances of the observation errors. The forward/backward revealed occasional large disagreements due to the Lagrangian model. Seasonal biases that will influence our final balance are small after removal of these periods $(0.12 \mathrm{ppm}$ over summer, and $0.1 \mathrm{ppm}$ over winter), limiting the impact on the inverse $\mathrm{CO}_{2}$ flux balance.

\subsection{Pre processing for boundary conditions}

The potential boundary inflow corresponds to the mole fraction from the $\mathrm{CT}_{v 09}$ inverse system using the TM5 transport model at $1^{\circ}$ resolution. We directly compared the mole fractions to observed mixing ratios from aircraft profiles at four different sites, each site being attributed to the closest boundary (or two for AAO and HIL sites) of the domain (cf. Sect. 2.5.2). In Fig. 5, we present the model-data mismatch in the PBL (blue letters), in the free troposphere (red letters), and the difference of the averaged model-data mismatch over the PBL (black diamonds), computed at the exact flight times and locations. If several profiles were available over a week, we show here the averaged differences. In the figure, the letters correspond to the boundaries of the domain (East, West, North, South) for each week. The very large residuals in June (more than $20 \mathrm{ppm}$ ) are observable within the two lower levels of the PBL, where the TM5 model is usually underestimating the vertical mixing (vertical profiles show clear unexpected gradients during convective days). We used the differences of the averaged mixing ratios over the higher levels of the PBL (black diamonds) to avoid these large differences in the lower levels of $\mathrm{CT}_{v 09}$.

In Fig. 6 (a), we present the histogram of the residuals between the aircraft data and the $\mathrm{CT}_{v 09}$ mixing ratios. The averaged model-data mismatch (or bias) is about $1.17 \mathrm{ppm}$ over summer (week 1 to 12 ) and 0.55 ppm over the 7 months. We investigate the impact of the 7-month bias on the final inverse flux balance over the region in Sect. 4.1. In Fig. 6 (b), no bias toward higher or lower mixing ratios is observed. We conclude here that, without the aircraft data correction, the weekly boundary conditions may contain large errors during critical periods, but on average over the 7 months, the bias remains modest $(0.55 \mathrm{ppm})$.

\section{4 $\mathrm{CO}_{2}$ flux time series}

The temporal variability observed at the local level using eddy-flux tower measurements is used to evaluate the posterior fluxes over two different ecosystem types. While this comparison is limited by representation errors, we believe that it is valid to compare the temporal patterns in both flux estimates. We compared our results by selecting the posterior fluxes in pixels where one ecosystem type covers more than $40 \%$ of the landscape. In Fig. 7a, we present daily-daytime averages of the prior fluxes from Sibcrop compared to the observed fluxes (averages of the two sites) from two eddy-flux tower measurements, with their standard deviations, representing the grassland ecosystems in the region (Brookings and Fermi). The two sites are significantly different in 2007 resulting in a large representation error (in green in Fig. 7a). The maximum of uptake in June indicates that the growing season peak for grassland ecosystems is outside our study period. The seasonality of this ecosystem is accentuated by the atmospheric observations (larger uptake in July compared to the prior flux) but the uptake in June remains too low, underestimated after inversion. The large boundary condition differences observed in Fig. 5, despite the corrections applied, might still affect the inverse fluxes during this period. After June, the inverse flux variablity is well correlated with the observed eddy-flux variability with a peak of uptake in mid-July and a decrease of the uptake in mid-August due to a drought in the North West of the domain.

Concerning the corn dominated area (cf. Fig. 8), the seasonal variability is well-correlated with the observations but varies depending on the location. The correlations over the 7 months with the 4 different sites are respectively $0.832,0.948,0.964$, and 0.950 with the prior compared to $0.91,0.955,0.965$, and 0.953 with the posterior fluxes. The correlation with the mean (average of the time series from the four sites) is about 0.94 with the prior fluxes, and 0.96 with the posterior. The mismatch (square root of the squared differences) is decreasing from $1.949 \mu \mathrm{mol} \mathrm{m}^{-2} \mathrm{~s}^{-1}$ to $1.915 \mu \mathrm{mol} \mathrm{m}^{-2} \mathrm{~s}^{-1}$ on average. We see here that the initial fluxes were highly correlated with the observations, with consistent but relatively small corrections after inversions on a weekly basis. In northern Illinois (East of the domain), the inverse fluxes show a late start to the growing season (end of June). The posterior fluxes show distinct temporal patterns for the West and the East of the domain. The observations indicate a large standard deviation across eddy-flux sites (as 


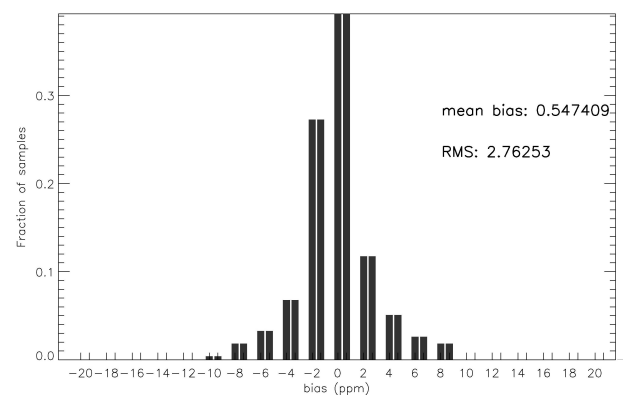

(a)

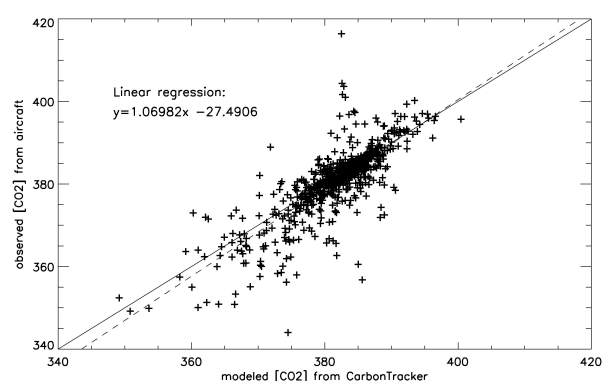

(b)

Fig. 6. Histogram of the model-data mismatch at the boundaries with the mean and standard deviation used to correct for the mean bias and to define uncertainties related to the boundaries in the inversion (on the left) and the linear regression between observed aircraft and $\mathrm{CT}_{v 09}$ modeled $\mathrm{CO}_{2}$ mixing ratios (on the right).

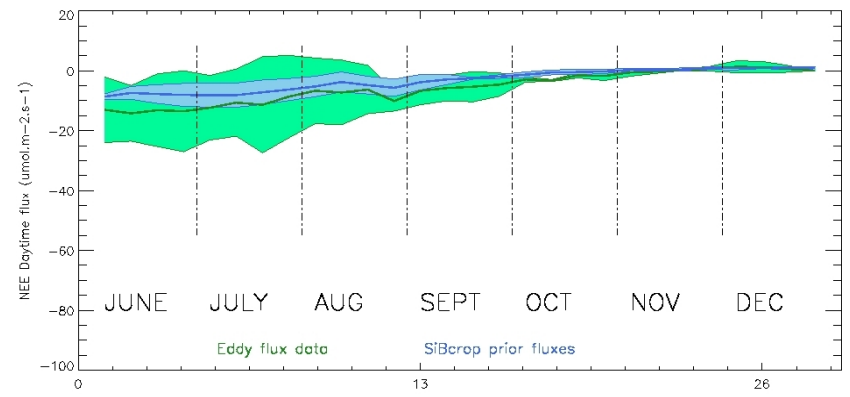

(a)

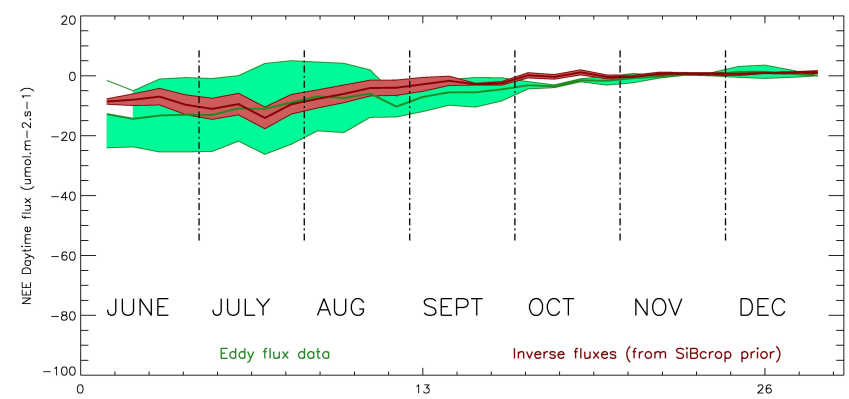

(b)

Fig. 7. Net Ecosystem Exchange comparison between Sibcrop grass-dominated pixels and eddy flux towers over grassland (Fermi prairie and Brookings) for the 7 months in umol. $\mathrm{m}^{2} \cdot \mathrm{s}^{-1}$ (in green): (a) SiBcrop prior (in blue) and (b) inverse fluxes (in red). The improvement after inversion remains limited in June but posterior fluxes (in red) are in better agreement with the observed fluxes on average over the period.

seen for grass), two of them being irrigated (less affected by the sporadic dry periods) increasing the overall flux uptake over summer in the Western Corn Belt. The absolute values of the posterior fluxes remain smaller than the observed fluxes, as corn occupies only about 40 to $60 \%$ of the pixel surface, mixed with soybean and other crop types. In the

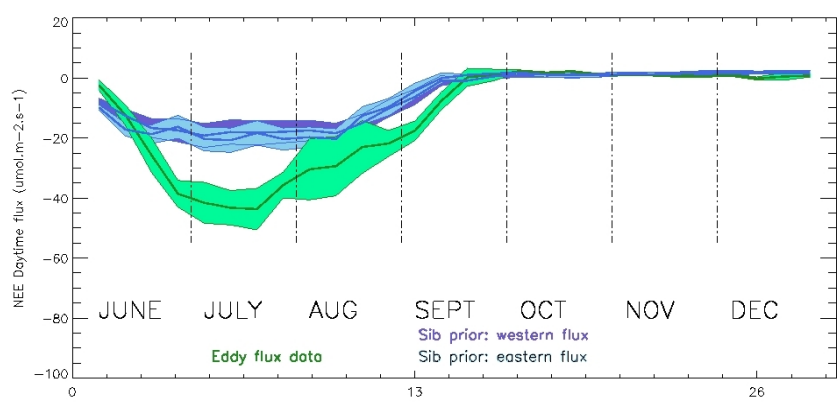

(a)

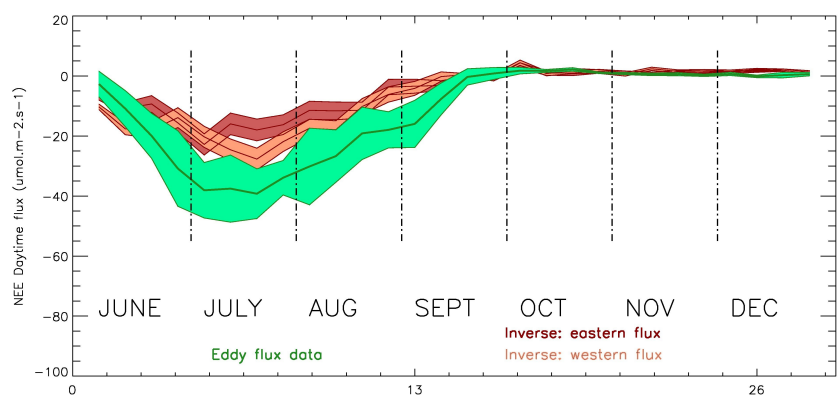

(b)

Fig. 8. Net Ecosystem Exchange comparison between Sibcrop corn-dominated pixels for the western (affected by droughts in July and August, in purple)) and the eastern part of the domain (in light blue), and eddy flux towers over corn fields (in green), irrigated or rainfed (Bondville, Rosemount G19 and G21, and Mead) in umol. $\mathrm{m}^{2} \cdot \mathrm{s}^{-1}$ : (a) SiBcrop prior (in blue) and (b) inverse fluxes (in red). Posterior fluxes are lower on average due to mixed vegetation types over the pixels.

model, the presence of soybean with a lower uptake compensates for the large corn uptake. For grassland, the vegetation fraction in the grass-dominated pixels is usually larger (up to $80 \%$ ) explaining the better agreement between the modeled fluxes and the observed eddy-flux data. Despite the smaller 


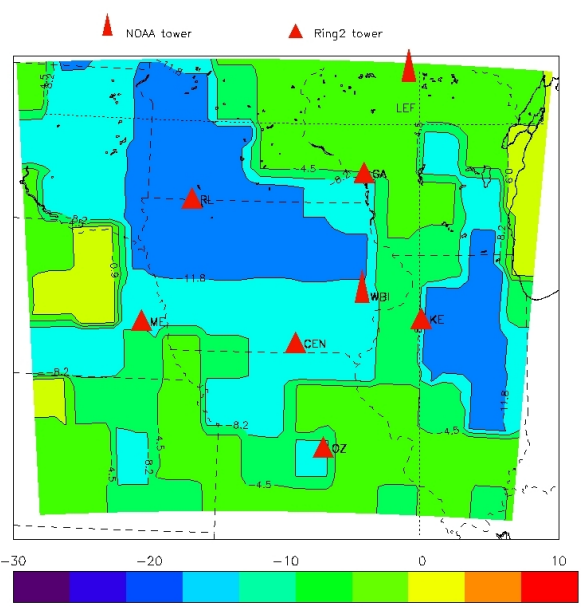

(a)

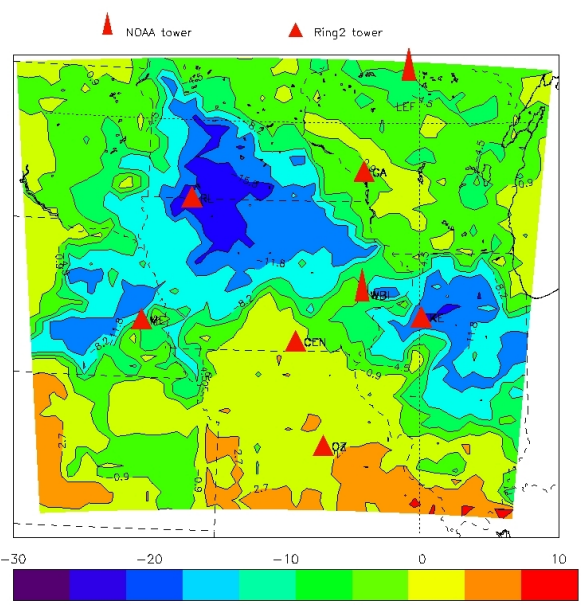

(c)

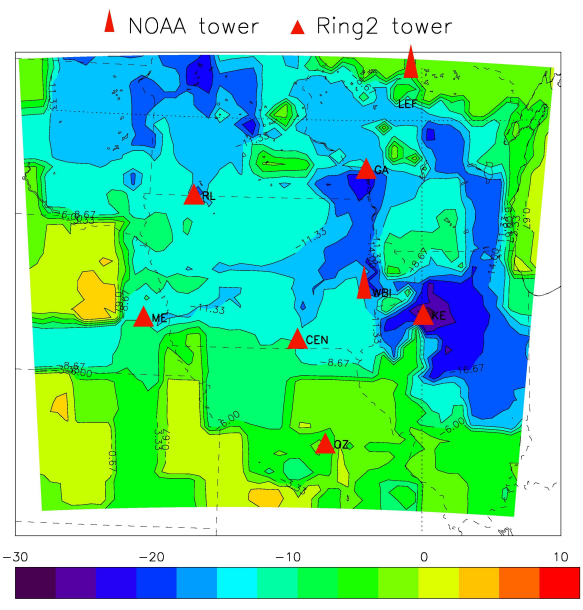

(b)

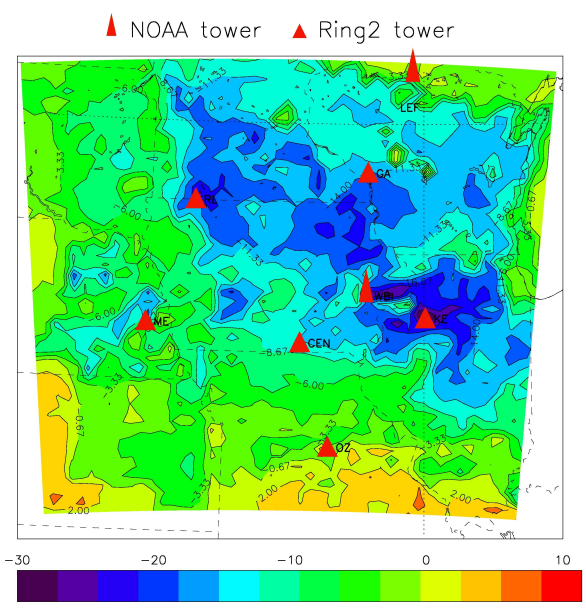

(d)

Fig. 9. Map of the $\mathrm{CO}_{2}$ fluxes accumulated from June to December in TgC.degree ${ }^{-2}$ over the MCI using CarbonTracker2009 inverse fluxes as prior: (a) prior and (b) posterior fluxes; and direct flux estimates from SiBcrop as prior fluxes: (c) prior fluxes and (d) posterior fluxes.

surface flux corrections in wintertime (i.e. limited improvement, discussed in Sect. 4.3), the posterior fluxes show a better correlation with the observed fluxes over the 7 months (cf. Fig. 7b), and no clear bias was introduced by the system. We discuss in Sect. 4.3 the capacity of the system to correct for wintertime flux biases.

\subsection{Convergence of the prior fluxes and impact on the posterior distribution}

We present in this section the spatial distribution of the prior and posterior fluxes, using sibcrop (Fig. $9 \mathrm{c}$ ) and $\mathrm{CT}_{v 09}$ (Fig. 9a) as two distinct priors. First, both posteriors show similar features in space, as a maximum of uptake in northern Illinois, and a stronger sink in Wisconsin, suggesting that the observational constraint is sufficient in both cases to de- tect the main spatial characteristics of the fluxes. But several areas remain correlated to the initial prior flux distribution, such as in Kansas and Nebraska, west of Mead (cf. Fig. 9b). Other areas show clear posterior flux structures that are not present in any prior. In northern Illinois for example (around Kewanee), the strong sink indicated by the posterior is well defined in both cases. This correction is consistent with high corn productivity with $+10 \%$ for the year 2007 compared to the past years as indicated by the annual USDA-NASS report 1 . Northern Iowa, usually very productive in terms of corn Net Primary Production, was affected by severe droughts during August 2007, whereas southern regions recorded averaged precipitations.

\footnotetext{
${ }^{1}$ www.nass.usda.gov/il
} 
In general, areas between tower sites show similar posterior flux distributions and magnitudes, resulting from the large constraint brought by the superimposed observation influence functions. The corn belt area, clearly defined in space in both priors, becomes wider with smaller spatial gradients.

\section{6 $\mathrm{CO}_{2}$ flux balance: final balance and uncertainties}

In this section, we investigate the sensitivity of the integral of the inverse fluxes across the region, and its sensitivity to the assumptions. These uncertainties come from the different choices one could make, all being realistic, with different degrees of complexity. Other tests are performed in Sect. 4 for additional errors or biases that may affect the inverse estimate but are not part of the present system, as e.g. the impact of remaining biases in boundary conditions that may not have been removed. These second tests help quantify the sensitivity of the system to the different components for future inverse systems, in other areas or using different prior fluxes. Using two different prior fluxes ( $\mathrm{CT}_{v 09}$ and $\mathrm{SiBcrop}$ ), we obtain similar posterior fluxes (cf. Table 1) though the prior fluxes were significantly different. We defined next several cases in which we dramatically increased or decreased uncertainties (prior flux errors, nighttime and daytime observation errors), inserted transport error correlations in time, modifying prior flux error correlations in space, and increased the time window over which the boundary conditions were optimized from one hour to four days. We increased our initial prior variances by $20 \%$ for the first case. For transport errors, we decreased the daytime standard deviations $\sigma_{B}$ to $2 \mathrm{ppm}$, about a factor two lower than our initial summertime standard deviations. We also considered the use of nighttime observations by decreasing the uncertainties to $10 \mathrm{ppm}$. The different cases are summarized in Table 1.

Increasing prior flux variance (larger $\sigma_{B}$ ) has little impacts on the posterior flux, similar to decreasing the observation error variances during the day (lower $\sigma_{R}^{\text {day }}$ ). This result, when compared to the large impact of temporal correlations in the observation errors $\left(\rho_{\left(X_{t}, X_{t+n}\right)} \neq 0\right)$, reinforces the importance of the covariances in our system (the structure of the errors), here having more impact on the regional fluxes than the daytime variances. Higher confidence in nighttime data $\left(\sigma_{R}^{\text {night }}=10 \mathrm{ppm}\right)$ shows the largest decrease of NEE on the final flux balance. This impact is consistent with the consistently lower nighttime mixing ratios simulated by WRFChem. Fitting the nighttime observations is translated into an increase of the positive nighttime flux, decreasing the net sink over the region. Considering the impact of observation error correlations in time when using $\mathrm{CT}_{v 09}$ as prior fluxes $\left(\rho_{\left(X_{t}, X_{t+n}\right)} \neq 0\right)$, the impact is lower (only $33 \mathrm{TgC}$ change compared to $41 \mathrm{TgC}$ change when using SiBcrop). We also examined the impact of using different time windows for the boundary conditions $\left(T_{b c}=90 \mathrm{~h}\right)$ and noticed a change of $16 \mathrm{Tg} \mathrm{C}$ on the 7-month regional balance. Finally, we simplified the prior error correlation by using a simple correlation length ( $L=300 \mathrm{~km})$, without considering ecosystem types $\left(\rho_{B}=f(\right.$ dist $\left.)\right)$.

The posterior uncertainties from our system are, over the 7-month period, about $30 \mathrm{TgC}$ (depending on the selected case). Considering the different setups we defined, the uncertainty in the regional balance due to assumptions in the inverse system is about $15 \mathrm{TgC}$, with a mean slightly weaker than the reference setup (mean balance of $-183 \mathrm{Tg} \mathrm{C} \pm 16 \mathrm{TgC}$ ). This quantity is a range of solutions but is not following a Gaussian distribution. We excluded here the low nighttime transport error case, this one being fundamentally incorrect. For example, the choice of temporal correlations in the observation errors or the structure of the prior errors are motivated by previous studies and one may argue about their relevance. We consider here that any assumption made in the system, if not well established, has to be tested and considered as an additional source of uncertainty. In Sect. 4.1, we present the different sources of uncertainties and combine these to our posterior uncertainties.

\section{Discussions}

\subsection{Boundary conditions and remaining uncertainties}

We applied a pre-treatment of the boundary concentrations by correcting model-data mismatch at the boundaries before inversion instead of adding aircraft data to the inverse system to correct for the $\mathrm{CO}_{2}$ inflow. The comparison between the observed and the simulated $\mathrm{CT}_{v 09}$ concentrations could lead to an incorrect quantification of the boundary inflow errors for two main reasons: first, the aircraft profiles, punctual observations over the column, are not representative of the entire boundary of $1000 \mathrm{~km}$ long and the entire week; and second, the PBL mixing ratios affected by vertical mixing errors in $\mathrm{CT}_{v 09}$ transport model (currently the TM5 model Krol et al., 2005) could be different in WRF-ChemCO ${ }_{2}$ when remixed by our PBL scheme. We computed boundary mixing ratios at the tower locations. Along their path within the simulation domain from the boundary to the tower location, $\mathrm{CT}_{v 09}$ mole fractions are redistributed on the vertical. The differences between $\mathrm{CT}_{v 09}$ and aircraft data at the boundaries might not be valid at the tower locations, because the vertical mixing in WRF-ChemCO ${ }_{2}$ modified the original vertical distribution of the $\mathrm{CT}_{v 09}$ mole fractions. Because TM5 model is affected by low vertical mixing in the lower atmospheric levels (levels one and two mainly), we only used differences integrated over the PBL.

In the inversion, we defined the inflow as time series, instead of influence functions and gridded boundaries, to limit the increase of the dimension of the state vector. The $\mathrm{CO}_{2}$ vertical distribution at the boundaries is also very sensitive to PBL dynamics and may contain large uncertainties at the pixel level if we grid the boundaries of our domain. Previous studies have also shown that the error reduction using 
Table 1. Regional $\mathrm{CO}_{2}$ flux balance from June to December 2007 in $\mathrm{TgC}$ over the MCI using Sibcrop and CarbonTracker2009 as prior fluxes in the reference setup (prior and posterior), then assuming larger uncertainties in the prior (= larger $\sigma_{B}$ ), more confidence in nighttime data i.e. $10 \mathrm{ppm}$ instead of $100 \mathrm{ppm}$ (=lower $\sigma_{R}^{\text {night }}$ ), more confidence in daytime data i.e. $2 \mathrm{ppm}$ instead of 3 ppm for the lower limit $(=1$ lower

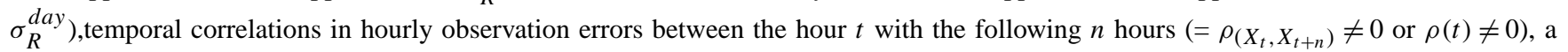
longer time period to correct for boundary influence $\left(=T_{b c}=90 \mathrm{~h}\right)$, and prior error correlations based on distance only $\left(\rho_{B}=f(L)\right)$.

\begin{tabular}{ccccccccc}
\hline & prior & post & large $\sigma_{B}$ & low $\sigma_{R}^{\text {night }}$ & low $\sigma_{R}^{\text {day }}$ & $\rho(t) \neq 0$ & $T_{b c}=90 \mathrm{~h}$ & $\rho_{B}=f(L)$ \\
\hline $\mathrm{SiBcrop}$ & -109 & -194 & -190 & -149 & -195 & -153 & -178 & -179 \\
$\mathrm{CT}_{v 09}$ & -198 & -215 & $/$ & $/$ & $/$ & -182 & $/$ & $/$ \\
\hline
\end{tabular}

aircraft data is limited by the shorter time window of available observations (Lauvaux et al., 2008). We decided here to use the aircraft observations in a pre-processing of the boundaries and not directly as observations in the inverse system. The aircraft profiles available once a week on average over few hours contain little information to optimize the weekly fluxes biases and the boundaries. Using our approach in the future, more sophisticated methods could be applied as data nudging including additional dataset from commercial flight $\mathrm{CO}_{2}$ profiles or satellite products where available.

Here, we investigate the impact of potential biases in the boundary concentrations by adding a constant change of $+1 \mathrm{ppm}$. On the 7 month regional balance, this bias leads to a change of $+45 \mathrm{Tg}$ C. As explained in Sect. 3.3, the vertical mixing errors in TM5 $\left(\mathrm{CT}_{v 09}\right)$ have a limited impact at the observation locations thanks to the remix of the lower part of the column along its path in the WRF simulation domain. This element is of major importance to avoid large differences as observed in the lower troposphere in the $\mathrm{CT}_{v 09}$ residuals (cf. Fig. 5 in red). The potential bias due to incorrect boundary conditions can be estimated at half a ppm (defined as $1 \sigma$ of the error distribution) based on the initial model-data mismatch using the NOAA aircraft vertical profiles. This bias is translated in terms of potential errors on the final balance into a $\pm 24 \mathrm{Tg}$ C. Because we are not considering the improvement of the boundary conditions thanks to the use of aircraft data, this error represents an upper limit on the 7-month balance. This value seems reasonable compared to the large sink of our region. But, because of the unique strength of the atmospheric sink due to the high corn productivity entirely harvested (responsible for the apparently large atmospheric sink), our region is not common and many other areas may suffer from this large potential bias compared to their relatively low annual flux (e.g. Göckede et al., 2010a). Further measurements will be needed to better constrain the error in the boundary conditions.

\subsection{Temporal window for the boundaries - what is the impact?}

The time length for the boundary conditions in our system, from hourly to a few days, has additional impacts on the correction of biases in the inflow. The surface fluxes are cor- rected on a weekly time scale. If the time resolution of the boundaries in the state vector is closer to one week, some signals originally attributed to the surface are transferred to the boundaries. But this assumption can be justified by the fact that inflow errors occur at the time scale of synoptic changes rather than the scale of the local dynamics. We investigated the two assumptions (one assuming rapid changes at the boundaries and the second slow changes driven by synoptic conditions) by changing the time period of the boundaries in the state vector as explained in Sect. 2.5.3. Table 1 shows that a change of the order of $16 \mathrm{TgC}$ was removed from the surface fluxes and transposed to the inflow. In order to compare the boundary condition corrections in both cases, we estimated the boundary condition impact on the optimized atmospheric concentrations. The first case, using hourly concentrations at each tower, shows large hour-tohour variations. We then averaged over the longer period of time $(90 \mathrm{~h})$ and noticed that the contribution from the boundaries can change by several ppm when using hourly concentrations at the boundaries or averages over several days. Weekly surface fluxes changed depending on the inflow averaging period. But the final surface flux balance remains similar in both cases, with only 0.3 to $0.8 \mathrm{ppm}$ (standard deviations of the corrections) reattributed to the boundary corrections, and similar mean corrections (about $0.4 \mathrm{ppm}$ in both cases). Over the 7 months, less than $0.5 \mathrm{ppm}$ of the $90 \mathrm{~h}-$ averaged hourly boundary correction is due to the transfer of information from the surface to the boundary concentrations, implying an additional standard deviation of about 7 to $10 \mathrm{Tg} \mathrm{C}$ in the final regional carbon balance. At this point, the time window for boundary conditions will remain an underconstrained parameter in our system, considering the related uncertainty as additional errors in the final balance. Further study will focus on the autocorrelation of the residuals to define the time scale of the inflow errors.

\subsection{What is the real potential of convergence of the system?}

The impact of the prior flux spatial distribution affects several areas despite the large amount of atmospheric observations used to constrain the surface fluxes. For the 7-month balance, both priors end up at relatively similar values around 
$-205 \mathrm{Tg} \mathrm{C} \pm 10 \mathrm{Tg} \mathrm{C}$. Two additional cases were designed to evaluate the potential of convergence of the system. The first case assumes an additional flux bias in summer and in winter, by multiplying the $\mathrm{SiBcrop}$ prior fluxes by 1.5 , i.e. increasing the seasonal signals considerably. This biased prior presents a larger 7-month sink ( $-164 \mathrm{Tg} \mathrm{C}$ instead of $-109 \mathrm{Tg} \mathrm{C})$ because of the large increase of the summer uptake compared to the relatively lower increase of the wintertime net positive flux. The results show that the summer bias is almost entirely removed ( $95 \%$ retrieved), but the winter time bias after inversion is partially retrieved, with a difference with the reference inversion of $0.95 \mathrm{Tg} \mathrm{C}$ per week on average, corresponding to a posterior 7 -month balance of $-185 \mathrm{Tg} \mathrm{C}$. It clearly indicates that the inverse system is limited in winter because of the larger boundary condition contribution compared to the surface flux signal. We computed the ratio of the boundary contribution to the surface flux contribution on hourly concentrations. In July, about 10 to $20 \%$ is due to boundary contribution versus 30 to $40 \%$ during winter. However, by including an additional $4.1 \mathrm{Tg} \mathrm{C}$ per week in winter, the inversion corrected for $77 \%$ of this bias.

The second case uses a SiBcrop simulation affected by unrealistic water stress in summer. The 7-month balance of this prior is close to zero $(-1.9 \mathrm{TgC})$. Starting with this erroneous prior flux, the posterior flux balance ends up at $-147 \mathrm{Tg} \mathrm{C}$. The inverse system, even if not able to retrieve or converge to previous inverse estimates in this case, showed a large correction of the initial balance retrieving $80 \%$ of the reference posterior flux balance. It suggests that the observational constraint is large enough to reach a reasonable estimate despite the distant initial carbon balance. As shown in Sect. 3.6, the spatial structure may be affected by the initial flux distribution. But the regional balance itself is highly constrained by the observations. Further investigations will consider the impact of observations on the inverse fluxes for concentration tower network design.

The transport model errors were evaluated using aircraft data vertical profiles. Additional errors from the Lagrangian model were also quantified by a forward-backward comparison and reasonable biases were included in our final flux uncertainty assessment. Part of the errors were not considered due to the lack of data to evaluate the atmosphere dynamics, as the advection of air or the convection scheme. We tested the potential impact of the daytime observation errors (variances) in the system by decreasing uncertainties to $2 \mathrm{ppm}$, and little impact affected our results (less than $1 \mathrm{Tg} \mathrm{C}$ change). Only uncertainties decreased in this case, with an underestimation of the posterior variances. Nighttime prior errors appeared more critical in our system. This result is consistent with past studies (e.g. Lauvaux et al., 2008) that showed the importance of the nighttime flux signals in the daytime observations to constrain the overall flux balance, affected by incorrect nighttime transport. Even though we almost removed the nighttime observations in our system $\left(\sigma_{R}=100 \mathrm{ppm}\right)$, transport model errors during nighttime af- fect the daytime observation signals. This result explains also the strong impact of temporal error correlations reinforcing the impact of transition period observations (morning and evening). The performances of actual mesoscale models during nighttime (or more generally during stable conditions) have to be improved in the future to reduce actual uncertainties, despite the absence of nighttime data use in the inverse system.

Finally, the posterior uncertainties of the inverse fluxes at about $30 \mathrm{TgC}$ and the different sensitivity tests $(16 \mathrm{TgC})$, including potential biases from the boundaries of about $24 \mathrm{Tg} \mathrm{C}$, gives a combined uncertainty of $34 \mathrm{Tg} \mathrm{C}$, excluding the additional $24 \mathrm{TgC}$ of potential additional biases for a regional sink of about $183 \mathrm{TgC}$. The present calculation is not a posterior uncertainty following a Gaussian distribution but an interval of confidence with an undefined distribution. Remaining errors are hard to quantify precisely (e.g. prior flux error correlations, complete transport model errors), and additional biases are likely to arise in future model intercomparisons. Further investigations will include transport evaluation and comparisons to independent estimates from inventory data at the regional level. High quality agricultural inventories made in the area (West et al., 2011) will allow the comparison to independent annual estimates of the regional carbon balance.

\section{Conclusions}

We presented here an inverse flux estimate at high resolution over the corn belt area for 2007 using eight $\mathrm{CO}_{2}$ concentration towers and two different prior fluxes. The sensitivity to the different assumptions was used to evaluate a more complete final uncertainty for our inverse flux balance. Boundary conditions were corrected with aircraft data profiles, potentially leading to an error (or a potential bias) of about $24 \mathrm{Tg} \mathrm{C}$ over the 7 months. But more critical is the impact of nighttime transport model errors and temporal error correlations in the simulated concentrations. Total uncertainties are about $34 \mathrm{TgC}$ including $16 \mathrm{Tg} \mathrm{C}$ from the assumptions made in the system, $30 \mathrm{Tg} \mathrm{C}$ from the prior and the transport model, and $24 \mathrm{TgC}$ of potential bias from the boundary conditions. The impact of boundary conditions is independent of the regional balance but only of the domain size, limiting the actual method to regions presenting large annual flux balances (more than $20 \mathrm{Tg} \mathrm{C}_{\text {year }}{ }^{-1}$ for a $10^{6} \mathrm{~km}^{2}$ domain). The degree of convergence indicates a robust signal for a sink of about $180 \mathrm{Tg} \mathrm{C}$ for the June to December period. Spatial patterns inherited from the prior fluxes were still detectable in the posterior fluxes especially on the sides of the domain, despite the large observational constraint. The atmospheric signal remains large enough to constrain the regional flux balance but spatial distribution required that influence functions from different towers were super-imposed. Clear spatial patterns in the posterior fluxes were identified (as the 
strong uptake in northern Illinois for the present year) despite the use of different priors.

Acknowledgements. We thank Andy Jacobson from NOAA/ESRL division for discussions and support with CarbonTracker products, Arlyn Andrews from NOAA/ESRL division for data support and management for the West Branch tall tower, Colm Sweeney and Gabrielle Petron from NOAA/ESRL division for data from the aircraft program, Tim Griffis from University of Minnesota for his comments and the eddy-covariance flux data from Rosemount, Shashi Verma and Andrew Suyker from University of NebraskaLincoln for eddy-covariance flux data from Mead, Tilden Meyers from NOAA/ARL division for eddy-covariance flux data from Brookings and Bondville, and Roser Matamala from Argonne National Laboratory for eddy-covariance flux data from Fermi. This research was supported by the Office of Science (BER) US Department of Energy, Terrestrial Carbon Program, the US National Aeronautics and Space Administration's Terrestrial Ecology Program, and the US National Oceanographic and Atmospheric Administration, Office of Global Programs, Global Carbon Cycle program.

Edited by: C. Gerbig

\section{References}

Ahmadov, R., Gerbig, C., Kretschmer, R., Koerner, S., Neininger, B., Dolman, A. J., and Sarrat, C.: Mesoscale covariance of transport and $\mathrm{CO}_{2}$ fluxes: Evidence from observations and simulations using the WRF-VPRM coupled atmosphere-biosphere model, J. Geophys. Res., 112, D22107, doi:10.1029/2007JD008552, 2007.

Baker, D. F., Law, R. M., Gurney, K. R., Rayner, P., Peylin, P., Denning, A. S., Bousquet, P., Bruhwiler, L., Chen, Y.H., Ciais, P., Fung, I. Y., Heimann, M., John, J., Maki, T., Maksyutov, S., Masarie, K., Prather, M., Pak, B., Taguchi, S., , and Zhu, Z.: TransCom 3 inversion intercomparison: Impact of transport model errors on the interannual variability of regional $\mathrm{CO}_{2}$ fluxes, 1988-2003, Global Biogeochem. Cy., 20, 439, doi:10.1029/2004GB002, 2007.

Baker, J. and Griffis, T.: Examining strategies to improve the carbon balance of corn/soybean agriculture using eddy covariance and mass balance techniques, Agri. Forest Meteorol., 128, 163-177, doi:10.1016/j.agrformet.2004.11.005, 2004.

Bousquet, P., Peylin, P., Ciais, P., Quéré, C. L., Friedlingstein, P., and Tans, P. P.: Regional changes in carbon dioxide fluxes of land and oceans since 1980, Science, 290, 1342-1346, 2000.

Butler, M. P., Davis, K. J., Denning, A. S., and Kawa, S. R.: Using continental observations in global atmospheric inversions of $\mathrm{CO}_{2}$ : North American carbon sources and sinks, Tellus B, 62, 550-572, doi:10.1111/j.1600-0889.2010.00501.x, 2010.

Canadell, J. G., Le Qur, C., Raupach, M. R., Field, C. B., Buitenhuis, E. T., Ciais, P., Conway, T. J., Gillett, N. P., Houghton, R. A., and Marland, G.: Contributions to accelerating atmospheric $\mathrm{CO}_{2}$ growth from economic activity, carbon intensity, and efficiency of natural sinks, Proc. Natl. Acad. Sci., 104, 18866-18870, doi:10.1073/pnas.0702737104, 2007.

Carouge, C., Rayner, P. J., Peylin, P., Bousquet, P., Chevallier, F., and Ciais, P.: What can we learn from European continuous at- mospheric $\mathrm{CO}_{2}$ measurements to quantify regional fluxes Part 2: Sensitivity of flux accuracy to inverse setup, Atmos. Chem. Phys., 10, 3119-3129, doi:10.5194/acp-10-3119-2010, 2010.

Chen, F. and Dudhia, J.: Coupling an advanced land surfacehydrology model with the PennState-NCAR MM5 modelling system. Part1: model implementation and sensitivity, Mon. Weather Rev., 129, 569-585, 2001.

Chevallier, F., Viovy, N., Reichstein, M., and Ciais, P.: On the assignment of prior errors in Bayesian inversions of $\mathrm{CO}_{2}$ surface fluxes, Geophys. Res. Let., 33, L13802, doi:10.1029/2006GL026496, 2006.

Chevallier, F., Ciais, P., Conway, T. J., Aalto, T., Anderson, B. E., Bousquet, P., Brunke, E. G., Ciattaglia, L., Esaki, Y., Frohlich, M., Gomez, A., Gomez-Palaez, A. J., Haszpra, L., Krummel, P. B., Langenfelds, R., Leuenberger, M., Machida, T., Maignan, F., Matsueda, H., Morgui, J. A., Mukai, H., Nakazawa, T., Peylin, P., Ramonet, M., Rivier, L., Sawa, Y., Schmidt, M., Steele, P., Vay, S. A., Vermeulen, A. T., Wofsy, S. C., and Worthy, D.: $\mathrm{CO}_{2}$ surface fluxes at grid point scale estimated from a global 21year reanalysis of atmospheric measurements, J. Geophys. Res., doi:10.1029/2010JD013887, in press, 2010.

Corbin, K. D., Denning, A. S., Lokupitiya, E. Y., Schuh, A. E., Miles, N. L., , Davis, K. J., Richardson, S., and Baker, I. T.: Assessing the impact of crops on regional $\mathrm{CO}_{2}$ fluxes and atmospheric concentrations, Tellus B, 62, 521-532, doi:10.1111/j.1600-0889.2010.00485.x, 2008.

Crosson, E. R.: A cavity ring-down analyzer for measuring atmospheric levels of methane, carbon dioxide, and water vapor, Appl. Phys. B, 92, 403-408, 2008.

Dolman, A. J., Noilhan, J., Durand, P., Sarrat, C., Brut, A., Piguet, B., Butet, A., Jarosz, N., Brunet, Y., Loustau, D., Lamaud, E., Tolk, L., Miglietta, R. R. F., Gioli, B., Magliulo, V., Esposito, M., Gerbig, C., Krner, S., Galdemard, P., Ramonet, M., Ciais, P., Neininger, B., Hutjes, R. W. A., Macatangay, J. A. E. R., Schrems, O., Pérez-Landa, G., Sanz, M. J., Scholz, Y., Facon, G., Ceschia, E., and Beziat, P.: CERES, the CarboEurope Regional Experiment Strategy in Les Landes, South West France, May-June 2005, Bull. Am. Meteorol. Soc., 87, 13671379, doi:10.1175/BAMS-87-10-1367, 2006.

Enting, I. G.: Inverse Problems in Atmospheric Constituent Transport, Cambridge University Press, Cambridge, UK, 412 pp., 2002.

Francey, R. J., Tans, P. P., Allison, C. E., Enting, I. G., White, J. W. C., and Trolier, M.: Changes in oceanic and terrestrial carbon uptake since 1982, Nature, 373, 326-330, 1995.

Garman, K., Hill, K. A., Wyss, P., Carlsen, M., Zimmerman, J. R., Stirm, B. H., Carney, T. Q., Santini, R., and Shepson, P. B.: An airborne and wind tunnel evaluation of a wind turbulence measurement system for aircraft-based flux measurements, J. Atmos. Ocean. Technol., 23, 1696-1708, 2006.

Geels, C., Gloor, M., Ciais, P., Bousquet, P., Peylin, P., Vermeulen, A. T., Dargaville, R., Aalto, T., Brandt, J., Christensen, J. H., Frohn, L. M., Haszpra, L., Karstens, U., Rdenbeck, C., Ramonet, M., Carboni, G., and Santaguida, R.: Comparing atmospheric transport models for future regional inversions over Europe; Part 1: mapping the atmospheric $\mathrm{CO}_{2}$ signals, Atmos. Chem. Phys., 7, 3461-3479, 2007, http://www.atmos-chem-phys.net/7/3461/2007/.

Gerbig, C., Lin, J. C., Wofsy, S. C., Daube, B. C., Andrews, 
A. E., Stephens, B. B., Bakwin, P. S., and Grainger, C. A.: Toward constraining regional-scale fluxes of $\mathrm{CO}_{2}$ with atmospheric observations over a continent: 1 . Observed spatial variability from airborne platforms, J. Geophys. Res., 108, 4756, doi:10.1029/2002JD003018, 2003a.

Gerbig, C., Lin, J. C., Wofsy, S. C., Daube, B. C., Andrews, A. E., Stephens, B. B., Bakwin, P. S., and Grainger, C. A.: Toward constraining regional-scale fluxes of $\mathrm{CO}_{2}$ with atmospheric observations over a continent: 2. Analysis of COBRA data using a receptor-oriented framework, J. Geophys. Res., 108, 4757, doi:10.1029/2003JD003770, 2003b.

Gerbig, C., Lin, J. C., Munger, J. W., and Wofsy, S. C.: What can tracer observations in the continental boundary layer tell us about surface-atmosphere fluxes?, Atmos. Chem. Phys., 6, 539-554, doi:10.5194/acp-6-539-2006, 2006.

Gioli, B., Miglietta, F., Martino, B. D., Hutjes, R., Dolman, H., Lindroth, A., Schumacher, M., Sanz, M. J., Manca, G., Peressotti, A., and Dumas, E. J.: Comparison between tower and aircraftbased eddy covariance fluxes in five European regions, Agr. Forest Meteorol., 127, 1-16, 2004.

Göckede, M., Michalak, A. M., Vickers, D., Turner, D. P., and Law, B. E.: Atmospheric inverse modeling to constrain regional scale $\mathrm{CO}_{2}$ budgets at high spatial and temporal resolution, J. Geophys. Res., 115, D15113, doi:10.1029/2009JD012257, 2010a.

Göckede, M., Turner, D. P., Michalak, A. M., Vickers, D., and Law, B. E.: Sensitivity of a subregional scale atmospheric inverse $\mathrm{CO}_{2}$ modeling framework to boundary conditions, J. Geophys. Res., 115, D24112, doi:10.1029/2010JD014443, 2010b.

Gourdji, S. M., Hirsch, A. I., Mueller, K. L., Yadav, V., Andrews, A. E., and Michalak, A. M.: Regional-scale geostatistical inverse modeling of North American $\mathrm{CO}_{2}$ fluxes: a synthetic data study, Atmos. Chem. Phys., 10, 6151-6167, doi:10.5194/acp-10-61512010, 2010.

Grabon, J. S., Davis, K. J., Kiemle, C., and Ehret, G.: Airborne Lidar observations of the transition zone between the convective boundary layer and free atmosphere during the international $\mathrm{H}_{2} \mathrm{O}$ Project (IHOP) in 2002, Bound.-Layer Meteorol., 134, 61-83, 2010.

Griffis, T. J., Baker, J. M., Sargent, S. D., Erickson, M., Corcoran, J., Chen, M., and Billmark, K.: Influence of $\mathrm{C}_{4}$ vegetation on ${ }^{13} \mathrm{CO}_{2}$ discrimination and isoforcing in the upper Midwest, United State, Global Biogeochem. Cy., 24, GB4006, doi:10.1029/2009GB003768, 2010.

Gu, L., Meyers, T., Pallardy, S. G., Hanson, P., Yang, B., Heuer, M., Hosman, K. P., Riggs, J. S., Sluss, D., and Wullschleger, S.D.: Direct and indirect effects of atmospheric conditions and soil moistre on surface energy partitioning revealed by a prolonged drought at a temperate forest site, J. Geophys. Res., 111, D16102, doi:10.1029/2006JD007161, 2006.

Gurney, K. R., Law, R. M., Denning, A. S., Rayner, P. J., Baker, D., Bousquet, P., Bruhwiler, L., Chen, Y.-H., Ciais, P., Fan, S., Fung, I. Y., Gloor, M., Heimann, M., Higuchi, K., John, J., Maki, T., Maksyutov, S., Masarie, K., Peylin, P., Prather, M., Pak, B. C., Randerson, J., Sarmiento, J., Taguchi, S., Takahashi, T., and Yuen, C.-W.: Towards robust regional estimates of $\mathrm{CO}_{2}$ sources and sinks using atmospheric transport models, Nature, 415, 626-630, 2002.

Kaminski, T., Rayner, P. J., Heimann, M., and Enting, I. G.: On Aggregation Errors in Atmospheric Transport Inversions, J. Geo- phys. Res., 106, 4703-4715, 2001.

Krol, M., Houweling, S., Bregman, B., van den Broek, M., Segers, A., van Velthoven, P., Peters, W., Dentener, F., and Bergamaschi, P.: The two-way nested global chemistry-transport zoom model TM5: algorithm and applications, Atmos. Chem. Phys., 5, 417432, doi:10.5194/acp-5-417-2005, 2005.

Lauvaux, T., Uliasz, M., Sarrat, C., Chevallier, F., Bousquet, P., Lac, C., Davis, K. J., Ciais, P., Denning, A. S., and Rayner, P. J.: Mesoscale inversion: first results from the CERES campaign with synthetic data, Atmos. Chem. Phys., 8, 3459-3471, doi:10.5194/acp-8-3459-2008, 2008.

Lauvaux, T., Gioli, B., Sarrat, C., Rayner, P. J., Ciais, P., Chevallier, F., Noilhan, J., Miglietta, F., Brunet, Y., Ceschia, E., Dolman, H., Elbers, J. A., Gerbig, C., Hutjes, R., Jarosz, N., Legain, D., and Uliasz, M.: Bridging the gap between atmospheric concentrations and local ecosystem measurements, Geophys. Res. Lett., 36, L19809, doi:10.1029/2009GL039574, 2009a.

Lauvaux, T., Pannekoucke, O., Sarrat, C., Chevallier, F., Ciais, P., Noilhan, J., and Rayner, P. J.: Structure of the transport uncertainty in mesoscale inversions of $\mathrm{CO}_{2}$ sources and sinks using ensemble model simulations, Biogeosciences, 6, 1089-1102, doi:10.5194/bg-6-1089-2009, 2009b.

Law, R. M., Rayner, P. J., Steele, L. P., and Enting, I. G.: Data and modelling requirements for $\mathrm{CO}_{2}$ inversions using high frequency data, Tellus, 55B, 512-521, doi:10.1034/j.16000560.2003.0029.x, 2003.

Lokupitiya, E., Denning, S., Paustian, K., Baker, I., Schaefer, K., Verma, S., Meyers, T., Bernacchi, C. J., Suyker, A., and Fischer, M.: Incorporation of crop phenology in Simple Biosphere Model (SiBcrop) to improve land-atmosphere carbon exchanges from croplands, Biogeosciences, 6, 969-986, doi:10.5194/bg-6-9692009, 2009.

Martins, D. K., Sweeney, C., Stirm, B. H., and Shepson, P. B.: Regional surface flux of $\mathrm{CO}_{2}$ inferred from changes in the advected $\mathrm{CO}_{2}$ column density, Agric. For. Meteorol., 149, 1674-1685, doi:10.1016/j.agrformet.2009.05.005, 2009.

Matamala, R., Jastrow, D., Miller, R., and Garten, C.: Temporal changes in the distribution of $\mathrm{C}$ and $\mathrm{N}$ stocks in a restored tallgrass prairie in the U.S. Midwest, Ecol. Appl., 18, 1470-1488, 2008.

Meyers, T. and Hollinger, S.: An assessment of storage terms in the surface energy balance of maize and soybean, Agr. Forest Meteorol., 125, 105-115, 2004.

Miles, N. L., Richardson, S. J., Davis, K. J., Lauvaux, T., Andrews, A. E., West, T. O., Bandaru, V., and Crosson, E. R.: Large amplitude spatial and temporal gradients in atmospheric boundary layer $\mathrm{CO} 2$ mole fractions detected with a tower-based network in the U.S. Upper Midwest, J. Geophys. Res., accepted, 2011.

Nakanishi, M. and Niino, H.: An improved Mellor-Yamada level 3 model with condensation physics, Bound. Layer Meteorol., 111, 1-31, 2004.

Ogle, S., Davis, K., Andrews, A., Gurney, K., West, T., Cook, R., Parkin, R., Morisette, J., Verma, S., and Wofsy, S.: Science plan: Mid-Continent Intensive campaign of the North American Carbon Program, US Global Change Carbon Program North American Carbon Program, available online at: http: //www.nacarbon.org/nacp/mci.html, 2006.

Pérez-Landa, G., Ciais, P., Sanz, M. J., Gioli, B., Miglietta, F., Palau, J. L., Gangoiti, G., and Millán, M. M.: Mesoscale circula- 
tions over complex terrain in the Valencia coastal region, Spain Part 1: Simulation of diurnal circulation regimes, Atmos. Chem. Phys., 7, 1835-1849, doi:10.5194/acp-7-1835-2007, 2007.

Peters, W., Jacobson, A. R., Sweeney, C., Andrews, A. E., Conway, T. J., Masarie, K., Miller, J. B., Bruhwiler, L. M. P., Ptron, G., Hirsch, A. I., Worthy, D. E. J., van der Werf, G. R., Randerson, J. T., Wennberg, P. O., Krol, M. C., and Tans, P. P.: An atmospheric perspective on North American carbon dioxide exchange: CarbonTracker, Proc. Natl. Acad. Sci., 104, 1892518930, doi:10.1073/pnas.0708986104, 2007.

Peylin, P., Rayner, P. J., Bousquet, P., Carouge, C., Hourdin, F., Ciais, P., Heinrich, P., and AeroCarb Contributors: Daily $\mathrm{CO}_{2}$ flux estimate over Europe from continuous atmospheric measurements - Part 1 inverse methodology, Atmos. Chem. Phys., 5, 3173-3186, doi:10.5194/acp-5-3173-2005, 2005.

Richardson, S. J., Miles, N. L., Davis, K. J., Crosson, E. R., Rella, C., and Andrews, A. E.: Field testing of cavity ring-down spectroscopy analyzers measuring carbon dioxide and water vapor, J. Atmos. Oceanic Technol., 0739-0572, doi:10.1175/JTECH-D11-00063.1, 2011.

Rödenbeck, C., Gerbig, C., Trusilova, K., and Heimann, M.: A twostep scheme for high-resolution regional atmospheric trace gas inversions based on independent models, Atmos. Chem. Phys., 9, 5331-5342, doi:10.5194/acp-9-5331-2009, 2009.

Sarrat, C., Noilhan, J., Dolman, A. J., Gerbig, C., Ahmadov, R., Tolk, L. F., Meesters, A. G. C. A., Hutjes, R. W. A., Ter Maat, H. W., Pérez-Landa, G., and Donier, S.: Atmospheric $\mathrm{CO}_{2}$ modeling at the regional scale: an intercomparison of 5 meso-scale atmospheric models, Biogeosciences, 4, 1115-1126, doi:10.5194/bg-4-1115-2007, 2007a.

Sarrat, C., Noilhan, J., Lacarrìe, P., Donier, S., Lac, C., Calvet, J. C., Dolman, A. J., Gerbig, C., Neininger, B., Ciais, P., Paris, J. D., Boumard, F., Ramonet, M., and Butet, A.: Atmospheric $\mathrm{CO}_{2}$ modeling at the regional scale: Application to the CarboEurope Regional Experiment, J. Geophys. Res., 112, D12105, doi:10.1029/2006JD008107, 2007b.

Schuh, A. E., Denning, A. S., Corbin, K. D., Baker, I. T., Uliasz, M., Parazoo, N., Andrews, A. E., and Worthy, D. E. J.: A regional high-resolution carbon flux inversion of North America for 2004, Biogeosciences, 7, 1625-1644, doi:10.5194/bg-71625-2010, 2010.

Skamarock, W. C., Klemp, J. B., Dudhia, J., Gill, D. O., Barker, D. M., Wang, W., and Powers, J. G.: A Description of the Advanced Research WRF Version 2, National Center of Atmospheric Research, Boulder, CO, USA, 100 pp., 2005.
Stephens, B. B., Gurney, K. R., Tans, P. P., Sweeney, C., Peters, W., Bruhwiler, L., Ciais, P., Ramonet, M., Bousquet, P., Nakazawa, T., Aoki, S., Machida, T., Inoue, G., Vinnichenko, N., Lloyd, J., Jordan, A., Heimann, M., Shibistova, O., Langenfelds, R. L., Steele, L. P., Francey, R. J., and Denning, A. S.: Weak Northern and Strong Tropical Land Carbon Uptake from Vertical Profiles of Atmospheric $\mathrm{CO}_{2}$, Science, 316, 1732-1735, doi:10.1126/science.1137004, 2007.

Sweeney, C., Karion, A., Wolter, S., Neff, D., Higgs, J. A., Heller, M., Guenther, D., Miller, B., Montzka, S., Miller, J., Conway, T., Dlugokencky, E., Novelli, P., Masarie, K., Oltman, S., and Tans, P.: Carbon dioxide climatology of the NOAA/ESRL Greenhouse Gas Aircraft Network, Journal of Geophysical Research, in prep., 2011.

Tans, P. P., Fung, I. Y., and Takahashi, T.: Observational constraints on the global atmospheric $\mathrm{CO}_{2}$ budget, Science, 247, 14311438, 1990.

Tarantola, A.: Inverse Problem Theory and Methods for Model Parameter Estimation, SIAM, (ISBN 0-89871-572-5), 2004.

Uliasz, M.: Lagrangian particle modeling in mesoscale applications, in: Environmental Modelling II, edited by: Zanetti, P., Computational Mechanics Publications, 71-102, 1994.

Verma, S. B., Dobermann, A., Cassman, K. G., Walters, D. T., Knops, J. M., Arkebauer, T. J., Suyker, A. E., Burba, G. G., Amos, B., Yang, H., Ginting, D., Hubbard, K. G., Gitelson, A. A., and Walter-Shea, E. A.: Annual carbon dioxide exchange in irrigated and rainfed maize-based agroecosystems, Agr. Forest Meteorol., 131, 77-96, doi:10.1016/j.agrformet.2005.05.003, 2005.

Wang, J.-W., Denning, A. S., Lu, L., Baker, I. T., Corbin, K. D., and Davis, K. J.: Observations and simulations of synoptic, regional, and local variations in atmospheric $\mathrm{CO}_{2}$, J. Geophys. Res., 112, D04108, doi:10.1029/2006JD007410, 2007.

Wang, W., Davis, K. J., Cook, B. D., Butler, M. P., and Ricciuto, D. M.: Decomposing $\mathrm{CO}_{2}$ fluxes measured over a mixed ecosystem at a tall tower and extending to a region: A case study, J. Geophys. Res., 111, G02005, doi:10.1029/2005JG000093, 2006.

West, T. O., Bandaru, V., Brandt, C. C., Schuh, A. E., and Ogle, S. M.: Regional uptake and release of crop carbon in the United States, Biogeosciences, 8, 631-654, doi:10.5194/bg-8-631-2011, 2011.

Zhao, C. L., Tans, P. P., and Thoning, K. W.: A high precision manometric system for absolute calibrations of $\mathrm{CO}_{2}$ in dry air, J. Geophys. Res., 102, 5885-5894, 1997. 